\title{
Tsafon
}

Revue d'études juives du Nord

$79 \mid 2020$

Les Juifs du Nord et du Pas-de-Calais dans la Shoah

\section{La persécution vécue par trois enfants juifs, dans la zone rattachée à Bruxelles}

Maurice Baran-Marszak, Jeannette Rapoport, Zelda Segouriano

Danielle Delmaire

\section{OpenEdition}

\section{Journals}

Édition électronique

URL : https://journals.openedition.org/tsafon/2918

DOI : $10.4000 /$ tsafon.2918

ISSN : 2609-6420

\section{Éditeur}

Association Jean-Marie Delmaire

Édition imprimée

Date de publication : 1 juillet 2020

Pagination : 113-152

ISSN : 1149-6630

Référence électronique

Danielle Delmaire, "La persécution vécue par trois enfants juifs, dans la zone rattachée à Bruxelles », Tsafon [En ligne], 79 | 2020, mis en ligne le 01 juillet 2020, consulté le 27 juin 2021. URL : http:// journals.openedition.org/tsafon/2918; DOI : https://doi.org/10.4000/tsafon.2918 


\title{
La persécution vécue par trois enfants juifs, dans la zone rattachée à Bruxelles
}

\author{
Maurice Baran-Marszak \\ Jeannette Rapoport \\ Zelda Segouriano
}

Témoignages présentés par Danielle Delmaire*

Les témoignages reproduits ci-dessous ont été entendus durant la seconde partie de la rencontre qui eut lieu au Mémorial de la Shoah, le 8 décembre 2019. Les témoins étaient des enfants avant la guerre. Ils habitaient tous les trois à Dunkerque et tous les trois appartenaient à une famille qui avait immigré en France entre les deux guerres. Le port connaissant alors un développement économique qui suscitait des activités commerciales, quelques familles participèrent à l'essor de la ville.

Il était nécessaire de rassembler ces trois témoins lors de cette rencontre consacrée à l'originalité de la région du Nord et du Pas-deCalais dans l'histoire de la Shoah en France. En effet, tous trois peuvent évoquer leur vie avant la débâcle et la persécution sur ce littoral qui, dès l'été 1940, est devenu une zone encore plus particulière dans la zone dite " rattachée à Bruxelles ». En revanche, chacun a connu un itinéraire différent dès lors que les combats de mai-juin 1940 ont dévasté la ville de Dunkerque. Si à leur départ les itinéraires se ressemblaient, très vite ils se sont différenciés. Ces témoignages montrent donc combien la

\footnotetext{
${ }^{*}$ Université de Lille.
} 
persécution peut prendre des tours divers : il n'y a pas une situation identique et les réactions des familles ont divergé.

La rencontre ne s'est pas déroulée de manière linéaire en trois parties, d'emblée j'ai préféré donner la parole à chacun des témoins, alternativement, afin qu'ils évoquent les différents moments forts de leur parcours durant la guerre : la vie avant la guerre et le bombardement de Dunkerque en mai- juin 1940, la vie rendue difficile par les persécutions, les arrestations et le sauvetage ou la survie.

Le style oral a été conservé, sauf s'il y a des hésitations importantes ou des répétitions, afin de restituer la spontanéité du témoignage et parfois en conserver l'émotion. Les témoignages ne sont pas interrompus par des notes explicatives en bas de pages - sauf très rarement et dans ce cas l'explication est entre crochets - ceci dans un souci de favoriser une lecture, et aussi une écoute, continue. Des remarques complémentaires suivent les récits des témoins.

\section{La vie avant la guerre et dans la débâcle de mai-juin 1940}

\section{Maurice Baran-Marszak}

Voilà des photos. Ce sont les photos de mon papa et de ma maman. Ils étaient commerçants tous les deux, à Dunkerque. Ils faisaient les marchés, chaque jour de la semaine, dans une autre ville, et le mercredi et le samedi à Dunkerque.
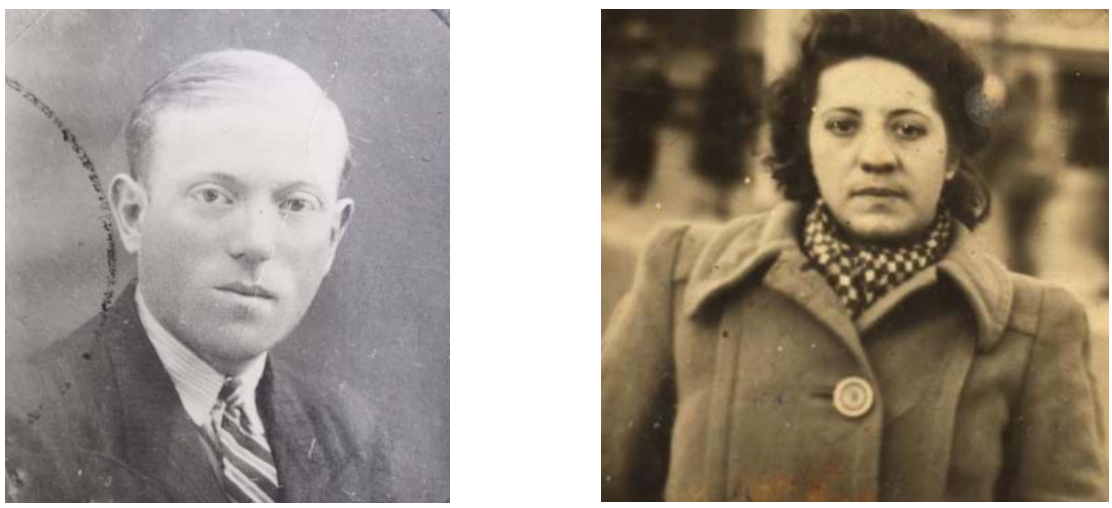

(archives familiales de Maurice Baran-Marszak)

C'est la photo de mon papa et à côté celle de ma maman, par cette photo c'est ce que je me rappelle d'elle. C'est, je crois, après la déportation de mon papa. Elle est dans une situation impensable, elle est 
d'une grande tristesse et se demande ce qu'il va se passer. Mon petit frère venait de naître, un ou deux mois avant. C'est terrible, terrible. Cette photo me touche énormément.

C'est la dernière photo de mes parents, celle que je chéris le plus. C'est là que je retrouve ma mère.

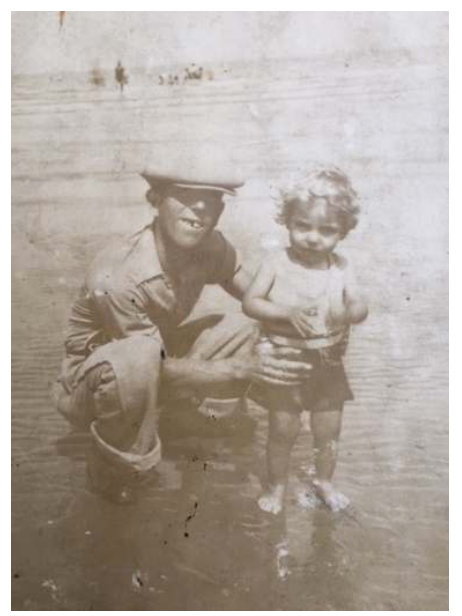

(archives familiales de Maurice Baran-Marszak)

Sur l'autre photo, je suis avec mon papa sur la plage de Malo-lesBains [près de Dunkerque], lieu fabuleux pour nous. Je dois avoir deux ans et demi. Je suis heureux à la plage avec mon papa, nous y allions très souvent.

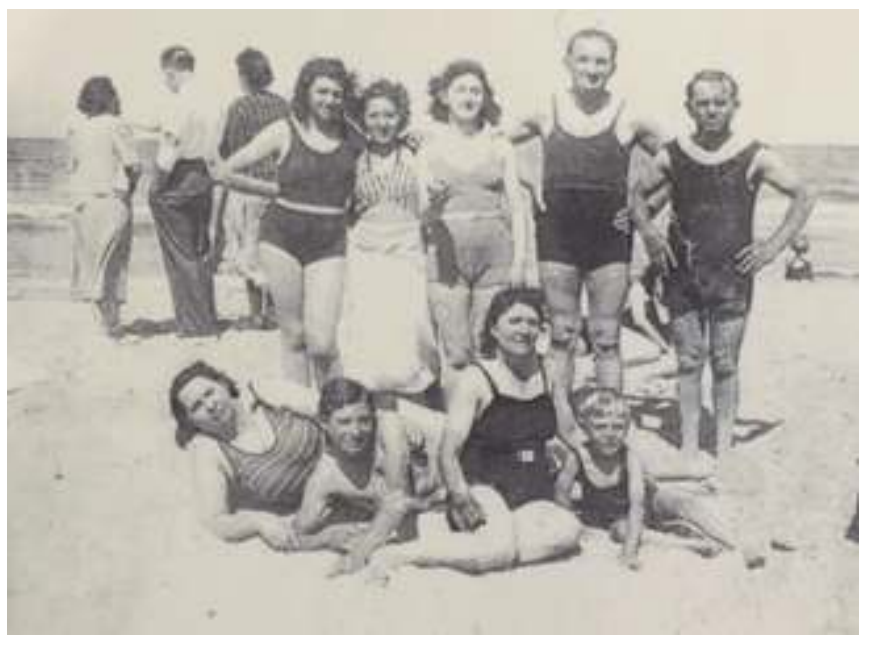

(archives familiales de Maurice Baran-Marszak) 
Sur la photo familiale, c'est en 1938 juste avant la guerre, il y a d'une part ma grand-mère Marie Yerkowski, qui venait d'Angleterre, elle était née Abramovitch mais en Angleterre elle s'appelait Abraham. Cette grand-mère, je l'ai chérie comme font tous les enfants envers leurs grands-parents. En haut, la deuxième personne, c'est ma maman. Elle est née en 1913. À côté, ce sont mes deux petites cousines, que j'adorais, dont le papa était cordonnier à Valenciennes. À côté encore, c'est mon grand-père qui bizarrement a disparu au camp du Vernet dans l'Ariège mais c'est une autre histoire. En bas, c'est ma tante et mon oncle Jacques, le frère de ma maman. Avec cette photo, je revis toute mon histoire que j'avais oubliée.

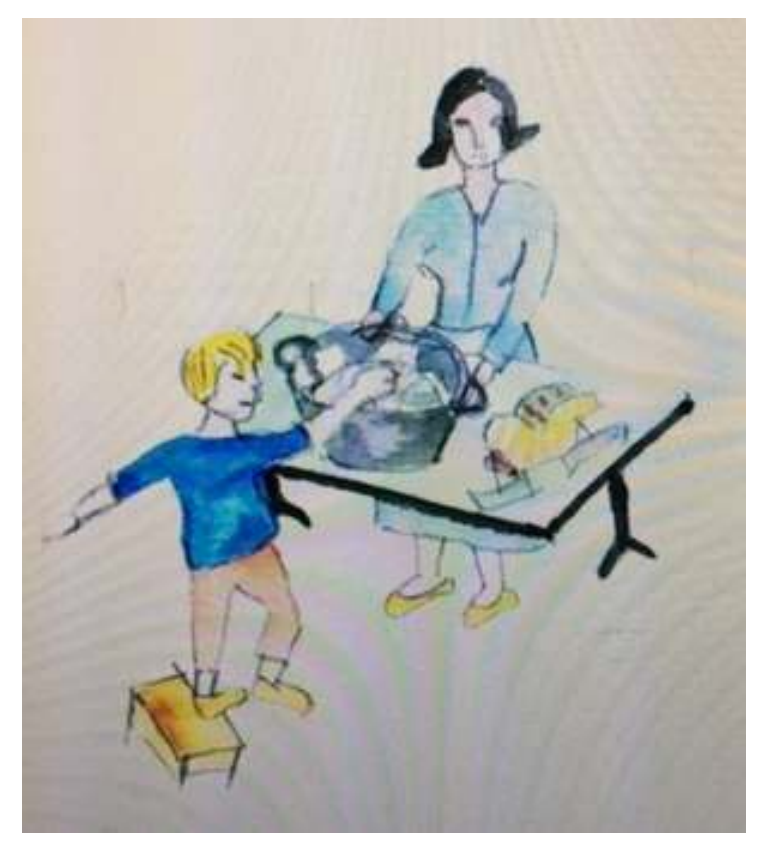

Dessin de Zlata Baran-Marszak

Illustration du livre de Maurice : Le p'tit garçon aux trois vies, éd. Pétra, 2019

Sur ce dessin, je suis représenté avec ma maman, je suis tout jeune garçon, à Dunkerque. Elle fait la lessive et, comme je suis curieux, je monte sur un petit banc pour voir, bien sûr le banc a basculé et je suis tombé. Mon bras a reçu l'eau bouillante.

Avant la guerre, mes parents avaient cherché une demoiselle pour me garder car ils travaillaient beaucoup. C'était Georgette qui venait de Loon-Plage, un petit bourg à $11 \mathrm{~km}$ de Dunkerque. Elle était chargée de me garder quand ils travaillaient. Nous habitions au premier étage de la 
rue de la Porte d'eau, et comme elle s'ennuyait un peu, petite ouvrière agricole enfermée dans un appartement, elle regardait souvent par la fenêtre. Et moi, bien sûr, toujours curieux, je regardais comme elle, je suis passé par la fenêtre et je suis tombé.

Mes parents faisaient les marchés place Jean Bart, avec la statue de Jean Bart. Petit garçon, j'adorais sauter sur les marches, au bas de la statue, les unes après les autres, jusqu'à épuisement.

\section{Danielle Delmaire}

On va peut-être arrêter là pour laisser les autres intervenants évoquer leurs souvenirs. Nous avons eu un aperçu de la vie d'une famille juive de Dunkerque, une famille heureuse. Maurice est fils unique, tendrement aimé de ses parents et entouré d'une grande amitié par Georgette, l'employée qui le garde. Il en reparlera. Je donne maintenant la parole à Jeannette Rapoport qui, elle aussi, a vécu une partie de son enfance à Dunkerque.

\section{Jeannette Rapoport (née Hubschman)}

Étant née en 1937, évidemment mes souvenirs personnels de Dunkerque sont quasiment insignifiants. On n'a jamais suffisamment demandé à ses parents de parler et quand ils ont disparu, on se demande pourquoi on ne les a pas interrogés.

Quelle est l'origine de ma famille ? Papa est venu de sa Galicie natale en France en 1923. Il désirait venir dans un pays, comme on disait, où Dieu est heureux! Il s'est engagé dès 1923 dans la Légion étrangère. Il est resté à peu près une dizaine d'années dans la Légion étrangère et il a obtenu la nationalité française. Il est allé en Algérie, au Maroc, en Indochine, il a passé beaucoup d'années sous l'uniforme.

Il a rencontré maman à Dunkerque. Elle arrivait de sa Pologne natale, du village d'Olkusz qui se trouve à $40 \mathrm{~km}$ d'Auschwitz. Pourquoi était-elle venue? Parce que comme beaucoup de jeunes filles juives polonaises, elle ne voulait pas vivre le sort qui leur était réservé. Elles devaient travailler dur; dès 11 ans, elles commençaient à travailler pour nourrir une partie de la famille, elles se mariaient puis avaient une famille nombreuse. Non, je crois que maman avait envie d'une autre vie. Elle est donc arrivée seule à Dunkerque, seule. C'était un périple à l'époque, d'arriver seul déjà pour un homme et les frais étaient importants. Il fallait travailler longtemps pour obtenir un visa. Et pour une jeune fille seule, réservée, c'était encore plus dur. De tout cela, on se 
rend compte quand on est une personne plus âgée et qu'on réfléchit bien après tous ces périples !

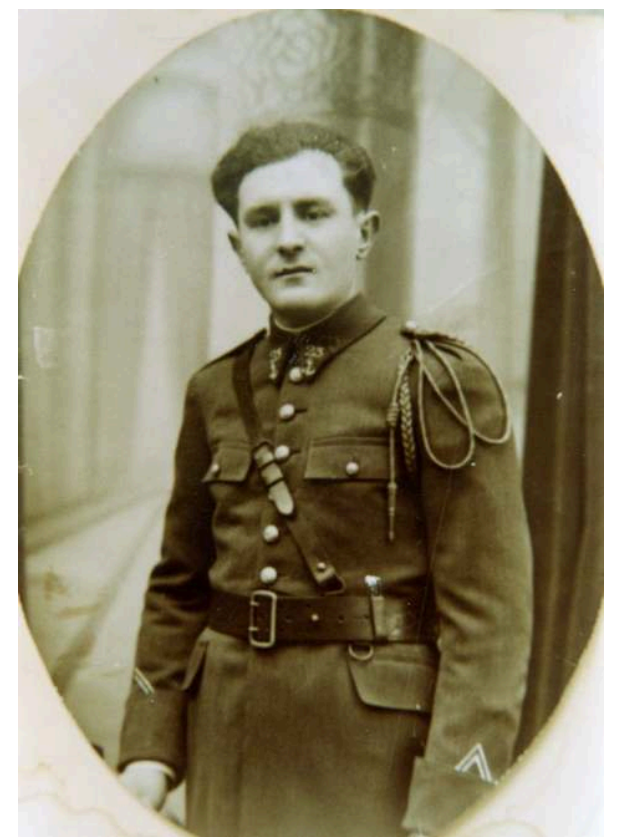

Le papa de Jeannette envoie, d'Indochine, une photo à Anna Macner, sa fiancée, et une carte postale (archives familiales de Jeannette Rapoport)

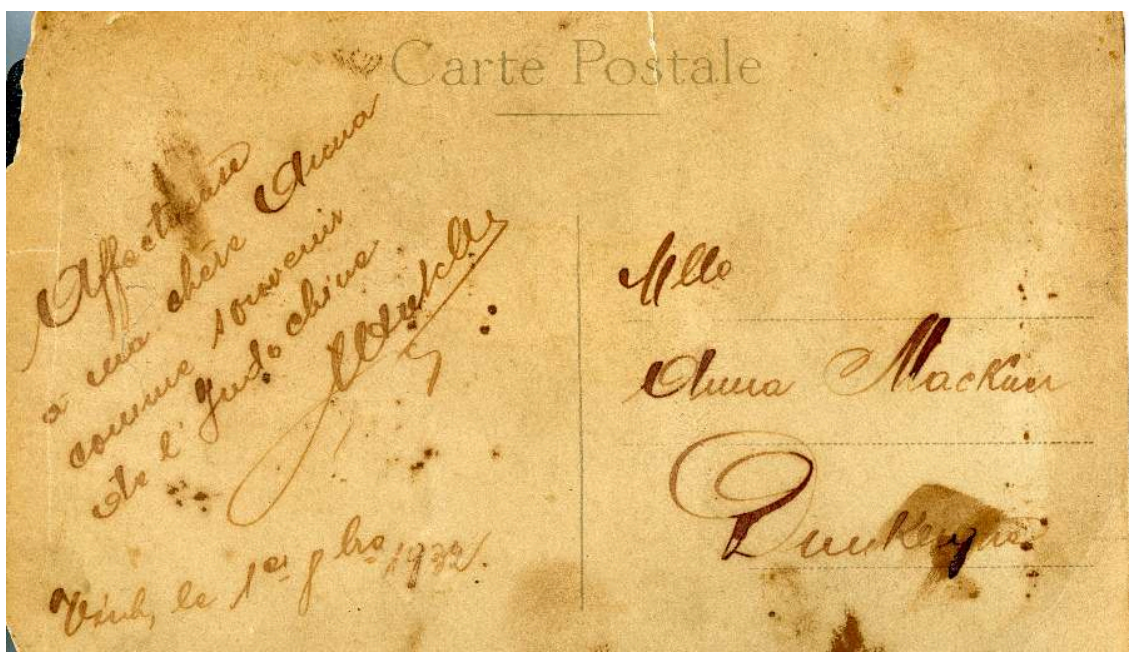

Elle travaillait chez une dame dont Rudy Rigaut m'a dévoilé les coordonnées et l'identité. Maman disait Madame Dina car elle avait du mal à prononcer Dinin. Elle a dû travailler de façon satisfaisante car cette 
dame l'a conservée. Celle-ci avait un fils qui était le copain de mon papa. Et quand il est rentré, lors d'une permission, $\mathrm{M}^{\mathrm{me}}$ Dinin et son fils ont dit à papa : "Viens, on va te présenter une jeune fille sympathique ». Et c'est comme cela que les choses se sont conclues et que mes deux frères et moi sommes nés.

Quant à vous dire ce qui s'est passé ? J'ai très peu de souvenirs de cette époque. Papa, bien sûr, a été mobilisé lors de la mobilisation générale pour être démobilisé quelques mois après, en 1940. Pendant ces quelques mois durant lesquels papa était mobilisé, maman m'a souvent raconté, elle courait avec mon frère et moi dans les rues de Dunkerque alors qu'elle attendait mon plus jeune frère Jacques. Elle courait sous les bombes. C'était en mai-juin 1940.

Non, je n'ai aucun souvenir personnel de cette époque, même pas des bombardements. Je ne me souviens pas d'avoir été à l'école. J'étais trop enfant pour avoir des souvenirs.

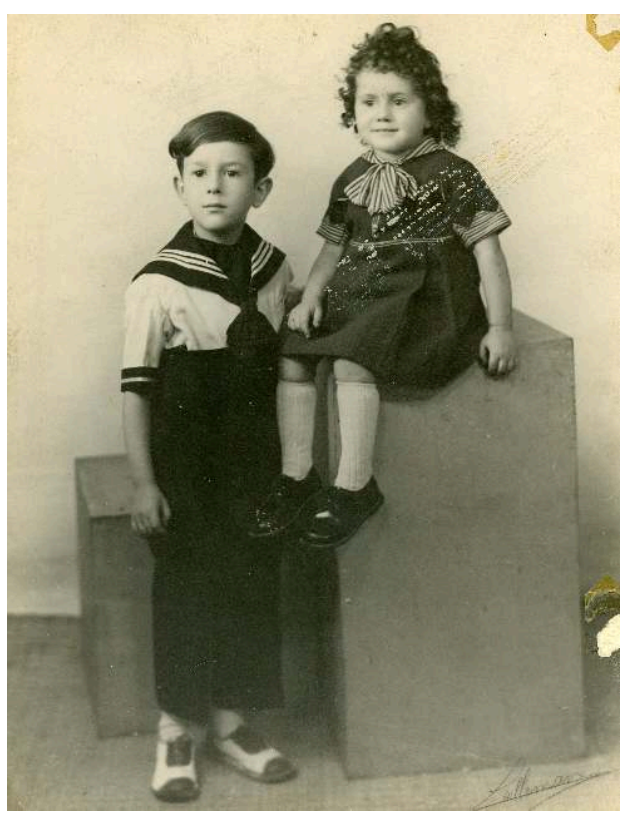

Jeannette et son frère aîné Bernard en 1940. La robe de Jeannette a été confectionnée par sa maman.

(archives familiales de Jeannette Rapoport)

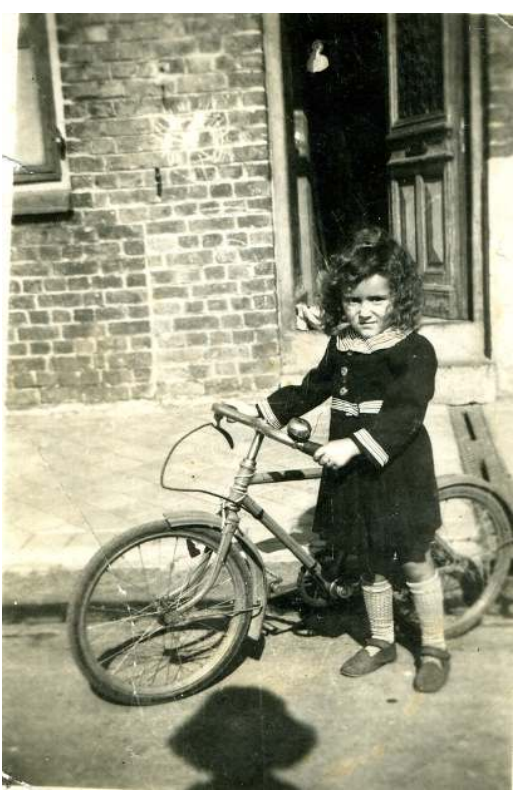

Jeannette et son vélo, en 1943 à Cambrai, juste avant une chute mémorable. (archives familiales de Jeannette Rapoport)

\section{Danielle Delmaire}

Nous allons donc écouter Zelda Segouriano maintenant. Vous avez vous souffert de ces bombardements de la bataille de Dunkerque en mai- 
juin 1940. Zelda, qui est née en 1925, se souvient de cette période et elle a beaucoup à nous raconter.

\section{Zelda Segouriano}

C'était horrible, il y avait des bombardements tous les soirs. On descendait à la cave et c'est devenu de plus en plus horrible. Dans la rue où nous habitions près de la place Jean Bart, tous les immeubles à côté du nôtre se sont écroulés. Mon père a décidé de fuir Dunkerque. Ce fut une horreur. Comme tout le monde, on était sur les routes, vous avez vu cela dans des films, on avait tout sur la voiture, le matelas, tout. Et puis on a été bombardés par les Allemands, sur la route à Spicker à une dizaine de $\mathrm{km}$ de Dunkerque. Et ma mère est morte dans ce bombardement. Moi, j'ai reçu un éclat d'obus au genou. J'ai toujours la cicatrice d'ailleurs, et voilà !

Et on s'est retrouvés refugiés à Lille car mon père connaissait une dame qui nous a hébergés.

\section{Danielle Delmaire}

Vous avez oublié de mentionner un épisode important dans cette fuite. Vous ne retrouvez plus votre papa, c'est important.

\section{Zelda Segouriano}

On était partis avec le pâtissier, qui habitait notre immeuble, et son fils qui avait le même âge que moi à un an près. Quand la bombe est tombée, tout le monde s'est échappé, ma mère a dû être touchée à la tête et elle est restée. Moi, je ne pouvais pas courir parce que j'avais très mal à la jambe. Le garçon a trouvé une brouette pour m'y mettre et il a poussé la brouette. On avait quatorze ans. Voilà. Et nous sommes partis dans une autre direction que celle de mon père.

Après je ne l'ai plus retrouvé et on était perdus. On a été accueillis pendant une semaine par des paysans, dans une ferme. On a fait des appels à la radio pour retrouver mon père et finalement il m'a retrouvée grâce à une annonce dans les journaux. Il a indemnisé ces paysans qui avaient été très, très gentils avec nous.

\section{Danielle Delmaire}

Dans cette bataille de Dunkerque, votre papa perd sa femme et il a cru perdre sa fille qu'il finit par retrouver. Puis vous allez à Lille, dès juin 1940. 


\section{Zelda Segouriano}

Il connaissait cette dame qui nous a aidés au péril de sa vie car lorsqu'on donnait asile à des juifs, on risquait autant qu'eux. Chez cette femme, à Lille, c'est là qu'on a été arrêtés. On habitait chez cette dame que mon père connaissait. Mon père a fait la bêtise de nous déclarer car mon père adorait la France et il disait: «Non, jamais les Français ne feront du mal aux juifs ». Moi, je lui disais : «Tu as tort d'aller à la préfecture » et on s'est retrouvés avec deux étoiles !

À Lille, j'ai continué mes études, au lycée pour préparer mon bac. Nous vivions plus ou moins clandestinement tout en allant à l'école. Mon père avait quelques ressources. Il avait de l'argent qu'il avait gagné. Il avait beaucoup d'argent liquide. Je sais que, lorsqu'il a été arrêté, il a donné beaucoup d'argent à la dame qui nous a hébergés.

\section{Danielle Delmaire}

Vous êtes déclarée car vous avez une carte d'identité que j'ai retrouvée dans les archives en Belgique puisque vous avez dû la remettre à l'administration de la caserne Dossin à Malines. Elle date d'octobre 1941 et vous habitez rue de Fleurus à Lille. Et pourtant vous étiez plus ou moins cachés.

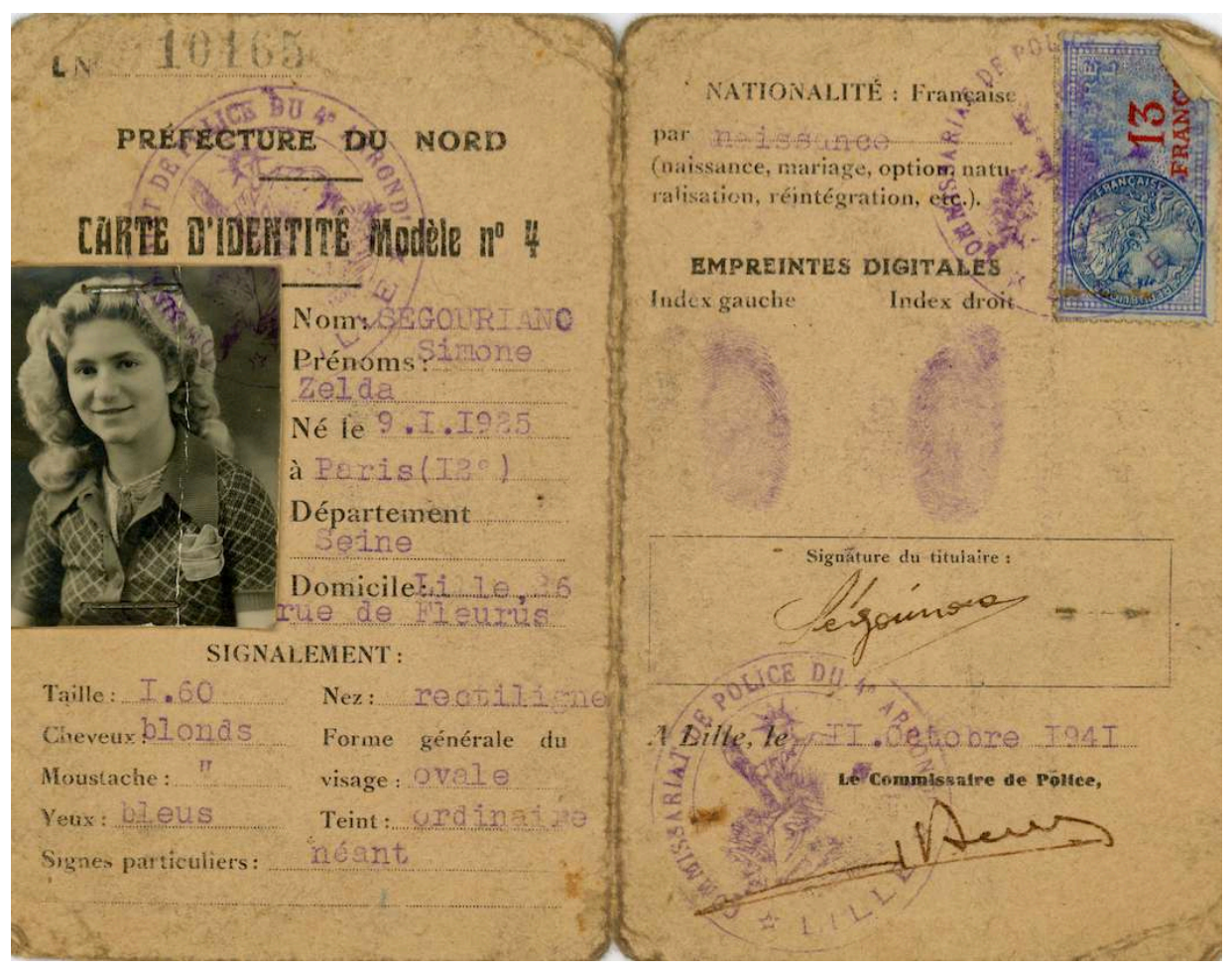




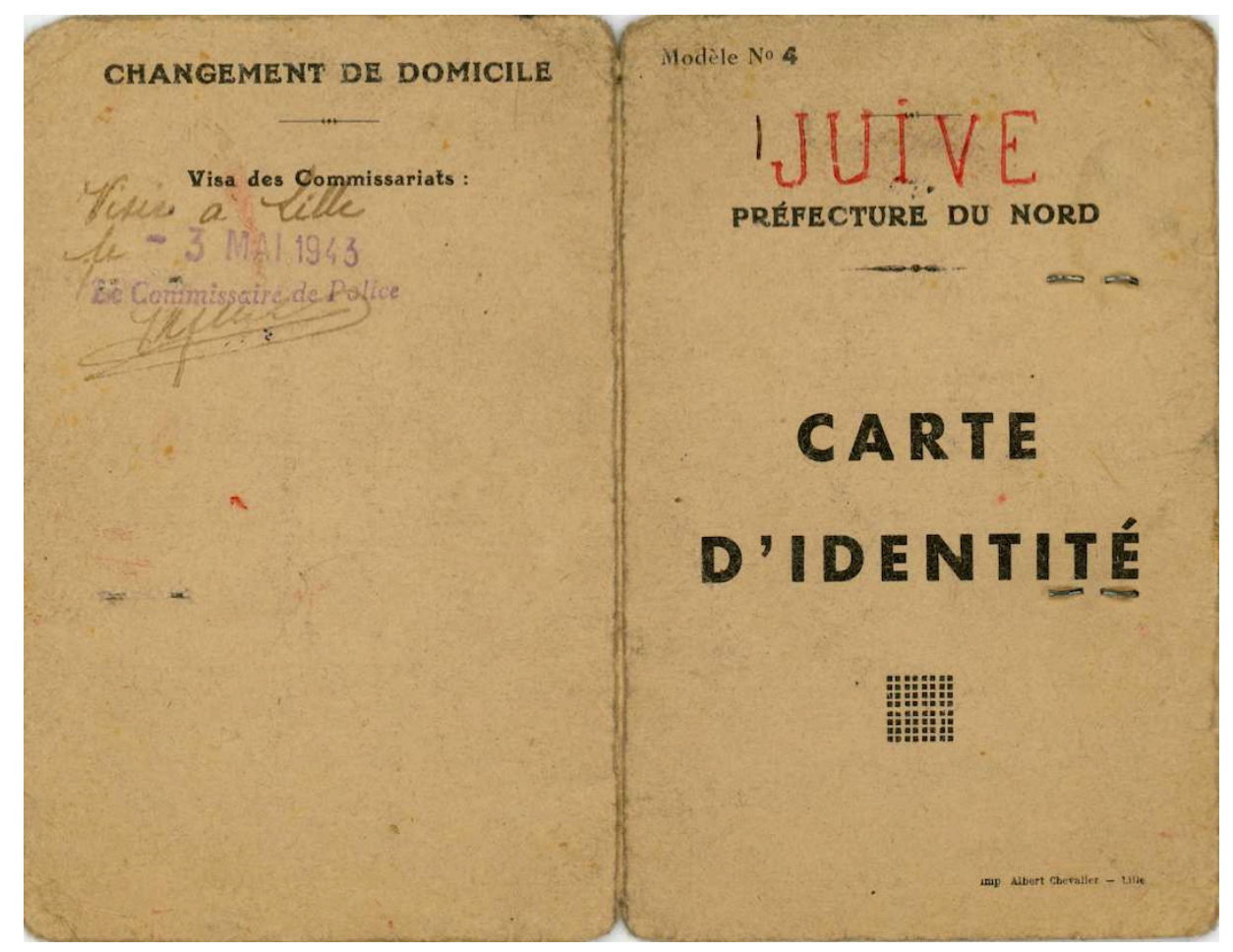

Carte d'identité de Zelda - Simone Segouriano, établie le 11 octobre 1941, renouvelée le 3 mai 1943.

Archives de la Caserne Dossin à Malines.

\section{Zelda Segouriano}

Oui, il fallait quand même faire attention. Mon père a été arrêté à cause d'une passion qu'il avait : il jouait au billard. Il était très fort. Il était champion du Nord, je crois. Il voyait régulièrement un monsieur, dans un café, qui était habillé en civil et qui parlait parfaitement le français et, en fait, c'était un Allemand. Mon père jouait au billard avec un Allemand mais il ne le savait pas! Mais le jour de notre arrestation, il était là habillé en Feldgendarme. Mon père s'est fait prendre comme cela.

\section{Danielle Delmaire}

Nous venons d'entendre un autre parcours d'une famille dunkerquoise. Il s'agit d'un couple immigré de Turquie, c'est important de préciser que les parents de Zelda sont originaires de la Turquie, pays allié à l'Allemagne. Ils ont leur enfant à Paris avant de s'installer à Dunkerque. La famille vit un drame lors de la bataille de Dunkerque. Le papa et sa fille se réfugient à Lille dès 1940. 


\section{Avant les arrestations 1940-1942/1943}

\section{Danielle Delmaire}

Sauf la famille Hubschman, de Jeannette Rapoport, les deux autres familles ont quitté Dunkerque. Revenons donc à la famille Baran qui elle aussi s'est réfugiée à Lille pour fuir les bombardements.

\section{Maurice Baran-Marszak}

L'invasion est foudroyante. Avec l'opération Dynamo, les Allemands bombardent le port et nous nous réfugions à la cave. Puis c'est l'exode : des milliers de gens fuient la Belgique et les Pays-Bas et passent sur les routes. Nous partons mais, arrivés à Berck, les Allemands nous ont rattrapés et nous rentrons à Dunkerque. Mes parents décident alors de partir pour Lille car il est impossible pour les juifs de rester sur le littoral. Mes grands-parents qui étaient restés à Dunkerque ont été contraints par l'administration française de quitter le Nord. Ils se sont dirigés vers la Bretagne puis sont restés au Mans quelque temps.

Nous sommes arrivés à Lille. J'avais des copains mais les choses se sont compliquées rapidement. Le statut des juifs et les lois scélérates antijuives nous empêchaient de faire du commerce. On nous supprimait toute possibilité de gagner sa vie. On était condamné à mourir de faim. La vie était difficile. Il a fallu aussi rendre le poste de radio, en 1942. Or mon père, qui était nerveux et inquiet, écoutait les informations à la radio toute la journée. Immédiatement, on a racheté un autre poste car on ne pouvait pas vivre sans informations. On allait écouter au $6^{\mathrm{e}}$ et, en 1942, on entendait déjà la BBC. On savait ce qui se passait en Libye et à Stalingrad et que les Allemands ne progressaient plus. Savoir que la guerre pouvait changer d'orientation nous donnait un espoir extraordinaire.

Nous étions à Lille avec Georgette. On ne pouvait pas avoir une bicyclette mais on lui en a trouvé une et elle parcourait, seule, la campagne et elle nous ramenait ce qu'elle avait trouvé comme victuailles. Nous étions inséparables. Elle était comme ma sœur. Elle avait 9 ans de plus que moi et j'étais toujours avec elle. Je la connaissais mieux que mes parents, c'était ma sœur.

J'ai dû porter l'étoile jaune obligatoire, en juin 1942. Ça a été terrible pour un enfant. Je suis allé très peu à l'école mais, dans le quartier, j'ai perdu tous mes petits copains. Leurs parents avaient peur que leurs enfants jouent avec des juifs. C'était une atmosphère terrible. 
On n'avait pas le droit d'aller dans les cafés, au cinéma. Cette Georgette, qui était extraordinaire, m'emmenait au cinéma, elle changeait ma veste. Je ne suis jamais tant allé au cinéma que lorsque c'était interdit. Je connaissais tous les acteurs, tous les chanteurs. J'entrais dans les squares interdits avec elle et elle m'emmenait sur les manèges.

Mon petit frère est né en mai 1942 et mon père a décidé qu'il fallait faire sa brit mila, même si c'était interdit. On a invité plein de monde et on a fait la fête. Puis mon père qui ne pouvait plus travailler et ne supportait plus d'être enfermé a décidé de passer en zone libre. Son commerce, c'était sa joie de vivre, il aimait bavarder avec les gens. Il a trouvé un passeur, à Lille, qui a fait monter tous ses clients dans son camion mais il les a conduits directement à la prison de Loos [près de Lille]. C'était un collaborateur. Mon père a donc été déporté par Malines par le premier convoi, le convoi I. Il est l'un des premiers déportés.

\section{Danielle Delmaire}

Nous parvenons donc à l'été 1942. Nous revenons à Dunkerque où vit toujours la famille Hubschman puisqu'elle n'a pas fui vers Lille et nous nous tournons vers Jeannette Rapoport née Hubschman pour savoir comment ses parents et elle-même ont continué à vivre à Dunkerque.

\section{Jeannette Rapoport}

Aussi incroyable que cela puisse paraître, nous sommes restés à Dunkerque jusqu'à la fin de 1942. Cela me paraît d'autant plus incroyable que je retrouve des documents qui prouvent que les autorités savaient que nous étions juifs, on savait qu'il y avait une famille juive puisqu'en 1941 papa a reçu l'ordre de rendre son poste de TSF, qui était précieux pour lui aussi. C'est un point d'interrogation. Un petit trou dans l'administration.

\section{Danielle Delmaire}

Vous auriez, en effet, dû être obligés de quitter le littoral qui devait être « sans juifs ».

\section{Jeannette Rapoport}

C'est fin 1942 que l'on reçoit l'obligation de partir dans un délai d'un mois et de dire où nous partons. Et où partons-nous? Nous arrivons en janvier 1943 à Cambrai. Maman a dit : «J'ai un frère à Cambrai » alors nous y sommes allés. Et quand nous sommes arrivés à Cambrai, en 
janvier 1943, il y avait les scellés sur la porte de la maison de mon oncle. C'est un de mes premiers grands souvenirs. Je me souviens bien des scellés sur la porte de la maison de mon oncle.

Ils avaient été déportés à Auschwitz, lui, son épouse et leur fils qui, comme moi, était né en 1937. On croyait qu'ils étaient encore à Cambrai. On ne savait pas qu'ils étaient partis.

Voilà les souvenirs.

\section{Les arrestations 1942-1943-1944}

Venons-en maintenant aux arrestations qui ont touché les trois familles. Elles ne se sont pas déroulées en même temps et nous allons les évoquer sans forcément suivre l'ordre chronologique. Nous allons commencer par écouter le récit de l'arrestation de Zelda, en octobre 1943, et sa déportation vers Malines et au-delà de Malines.

\section{Zelda Segouriano}

On a été arrêtés en octobre 1943, c'est tellement loin. Donc cet homme dont je vous ai parlé, qui jouait au billard avec mon père, est arrivé habillé en SS et il nous a dit : "Faites votre valise ». Et on s'est retrouvés à Malines, sans arrêt à la prison de Loos. Mais on a eu de la chance, on n'est pas restés longtemps à Malines où ce n'était pas très drôle. On n'est restés qu'une journée à Malines car on a tout de suite été déportés. Alors là j'ai à peine eu le temps de dire au revoir à mon père. Ils ont tout de suite séparé les hommes d'un côté et les femmes de l'autre. Je n'ai plus revu mon père depuis.

\section{Danielle Delmaire}

Il faut préciser pourquoi vous êtes arrêtés en dehors de la grande rafle du 11 septembre 1942. En octobre 1943, une rafle occasionne l'arrestation de plusieurs familles juives originaires d'Italie, de Hongrie et de Turquie. C'est le cas de la famille de Lili Leignel, née Rosenberg, dont les parents étaient originaires de Hongrie. Elle est bien connue car elle ne cesse de témoigner dans les écoles en France et même en Allemagne. Dans ces familles, les parents sont des ressortissants ou anciens ressortissants de pays alliés au Reich tandis que les enfants, nés en France, sont Français : c'est le cas de Zelda et de Lili Leignel. Ces adultes et leurs enfants ont donc subi un sort moins dévastateur que les juifs étrangers et français déportés de France. Au lieu de mourir 
brutalement à Auschwitz, ils sont condamnés à mourir à petit feu, les hommes à Buchenwald et les femmes et les enfants à Ravensbrück ! C'est pour cela que vous avez été arrêtée plus tardivement.

\section{Zelda Segouriano}

C'est tout de même une grande chance. Et ce qui me révolte c'est que si j'avais été arrêtée en tant que Française, je ne serais pas en train de parler en ce moment, je serais morte à Auschwitz. Ma chance a été que les Allemands ont cru que j'étais turque donc je me suis retrouvée dans un camp qui était un peu moins dur que celui d'Auschwitz, à Ravensbrück car ce n'était pas un camp d'extermination. C'était un camp où l'on mourait de sa belle mort.

\section{Danielle Delmaire}

Ou de sa mauvaise mort! Vous êtes donc à Ravensbrück et là quel est votre travail?

\section{Zelda Segouriano}

Alors là ! J'ai une amie, qui est juive, qui m'a demandé au cours d'un repas d'anniversaire : « Mais qu'est-ce que vous pouviez faire toute la journée ? » [Ton ironique et agacé]. On n'enfilait pas des perles et on cassait des cailloux, on réparait des routes, on avait un travail d'homme, terrible. Je ne sais pas comment vous expliquer. Et à côté de nous, il y avait toujours des femmes SS avec des bergers allemands qui nous mordaient les mollets dès qu'on s'arrêtait de travailler. Comment vous dire ? On était habillées avec une robe rayée en coton bleu et blanc, des tongs et pieds nus, un foulard sur la tête. C'est tout. Et encore à Ravensbrück, on a eu la chance de ne pas être rasées et de ne pas être tatouées comme à Auschwitz.

Après je n'ai pas eu la chance que quelqu'un tombe amoureux de moi comme Simone Veil ${ }^{1}$. Mais bon, j'ai eu la chance quand même que quelqu'un m'a remarquée, peut-être parce que je devais bien travailler, je ne sais pas, et je me suis retrouvée en usine et là c'était pour moi le paradis. C'était chez Siemens. On n'était plus avec des militaires, mais avec des ingénieurs. Ils étaient allemands et ils n'étaient pas terriblement affectueux mais enfin ils ne nous battaient pas. On travaillait mais on

\footnotetext{
${ }^{1}$ Dans son livre de souvenirs, Simone Veil raconte qu'une garde la trouve trop jolie pour mourir à Auschwitz et lui attribue un poste dans une usine Siemens où le travail est moins dur. Simone Veil, Une vie, Paris, Stock, 2007, p. 77-80.
} 
était à l'abri et puis on avait une soupe un peu plus épaisse que celle du camp.

\section{Danielle Delmaire}

Et après, quelques mois un peu plus tard, après votre arrivée à Ravensbrück?

\section{Zelda Segouriano}

La chance que j'ai eu encore, toujours grâce à la Turquie, c'est que je n'ai pas assisté à la délivrance du camp de Ravensbrück. J'ai été libérée à peu près deux ou trois mois avant car j'ai servi d'échange contre des prisonniers allemands qui étaient en Turquie et je me suis retrouvée à Istanbul. Là, j'ai eu très peur quand on a appelé mon nom. J'avais peur que ce soit pour être gazée ou je ne sais pas pourquoi.

Pas du tout. On nous a habillées en civil et on nous a emmenées dans un train normal et je me suis retrouvée à Istanbul après quelques jours de voyage, dans un hôtel mais prisonnière.

\section{Danielle Delmaire}

À Istanbul donc, vous avez servi de monnaie d'échange contre des prisonniers allemands et vous intégrez la prison d'où on les avait sortis.

\section{Zelda Segouriano}

Mais je n'étais pas libre là-bas, je ne pouvais pas sortir. Mais enfin, c'était une prison dorée quand même par rapport à ce que j'avais vécu.

J'ai dû me débrouiller toute seule pour regagner la France parce que je n'avais plus de famille. J'avais tout de même un cousin à Paris qui n'a pas été déporté et qui m'a envoyé de l'argent. C'est grâce à lui que j'ai pu prendre le bateau et revenir à Paris. J'avais aussi une cousine à Istanbul qui m'a apporté des vêtements et c'est elle qui a fait le lien avec mon cousin de Paris. L'argent que possédait mon cousin, c'était notre argent et tous les bijoux aussi de ma mère que mon père avait gardés. Il a pu les récupérer pour acheter le billet du bateau.

D'Istanbul, j'arrive donc à Marseille et là il y avait quelqu'un d'une association juive, je ne sais plus comment elle s'appelait, qui m'a apporté plein de vêtements : une valise, un tailleur, des chaussures, si bien que, lorsque je suis arrivée à Paris, mon cousin ne me reconnaissait pas et il m'a dit: «Tu n'as pas été tellement malheureuse, tu es drôlement bien sapée ! » 


\section{Danielle Delmaire}

Voilà donc la guerre vécue par une adolescente juive, appartenant à une famille juive immigrée de Turquie et installée à Dunkerque avant la guerre, une adolescente qui a survécu à la déportation. Revenons à Maurice Baran-Marszak dont le père était né en Pologne et qui vivait aussi à Dunkerque avant la guerre. À l'été 1942, votre famille vit à Lille et que se passe-t-il en septembre?

\section{Maurice Baran-Marszak}

C'était la grande rafle du 11 septembre 1942, dans le Nord et le Pas-de-Calais. Et comme pour toutes les rafles en France, cela s'est passé de bonne heure le matin. Vers 5-6 heures, on est venu frapper à la porte et, à cette heure-là, tout le monde était endormi. Quelqu'un, peut-être Georgette, a ouvert la porte et deux individus se sont précipités. Un Allemand, en vert-de-gris, criait «Schnell, schnell!» Puis un policier français en rajoutait : " On est pressé, allez un peu plus vite, préparez vite une valise ! » etc. Et ma pauvre mère, avec le bébé, mon petit frère avait trois mois, elle ne sait pas par où commencer et moi je tiens le jupon de ma mère parce qu'on m'a réveillé.

Et c'est Georgette, cette chère Georgette, qui trouve une valise et ce qu'on peut mettre dans la valise, en urgence. Comme le bébé est tout petit, on met un peu de layette et surtout des biberons. Le lait, il n'y en avait pas beaucoup, il y avait peut-être trois biberons. Et puis des couches et il n'y avait plus de place pour mettre des affaires pour nous. Et on nous a chassés, on nous a poussés hors de la maison.

On nous a fait monter dans un camion, au bas de la rue de la Vignette, dans lequel il y avait déjà plein de personnes : des enfants, des adultes. Et le camion est parti pour nous décharger à Fives, petite gare de marchandises et de voyageurs, dans la banlieue de Lille. Il y avait beaucoup de wagons et, surtout, la gare était engrillagée pour qu'on ne puisse pas se sauver.

Et là, il s'est passé une chose extraordinaire, il faut dire ce qui s'est passé ce jour-là. Un pasteur protestant, Marcel Pasche, qui était d'origine suisse et qui parlait l'allemand, avait eu en Suisse une formation antifasciste, anti-nazie. Il avait ses entrées à la Kommandantur de Lille car il y allait souvent pour les colonies d'enfants qu'il organisait. Il y a rencontré un certain Allemand [Friedrich Günther], un pasteur protestant de la même obédience que lui. Grâce à lui, le pasteur Pasche savait tout 
ce qui se tramait, si bien que le jour de la grande rafle, dont la date et le lieu étaient tenus secrets, il a su exactement ce qui allait se passer. Il a fait appel à ses ouailles protestantes et en particulier à la clinique Ambroise Paré dirigée par les infirmières $\mathrm{M}^{\text {elles }}$ Thérèse Matter et Éva Durrleman qui furent de grandes résistantes. Elles ont envoyé des volontaires sur le quai et ma mère a reconnu une personne et lui a demandé d'aller immédiatement à la maison pour chercher Georgette. Cette petite jeune fille de 18 ans, comment est-elle arrivée, comment estelle entrée sur le quai qui était gardé ? Elle voit ma maman et moi je tenais la jupe de ma maman, je ne voulais pas la lâcher. Maman a dit: « Tu prends Maurice et vous sortez». Alors j'ai pris la main de Georgette et un garde s'est précipité vers nous et a dit : «Qu'est-ce que vous faites, où est-ce que vous allez? » Alors Georgette, avec son accent du Nord, a répondu : « Le gamin, il a soif et il a envie de pisser et ici on ne peut même pas pisser et on ne peut même pas boire alors moi je l'emmène ». Et le gendarme a tourné la tête, encore un miracle, et il nous a laissé passer. Chose impensable ! C'est pour cela que je dis que je suis un mort-vivant car cela n'aurait pas dû être.

De la même façon, mon petit frère de trois mois, que ma maman tenait dans ses bras, est sauvé. Parmi les personnes protestantes venues sur le quai, ma maman a reconnu une infirmière de la clinique Ambroise Paré où elle a accouché trois mois plus tôt. L'infirmière dit : «Donneznous le bébé, nous allons le garder». D’abord ma maman a refusé. Imaginez, se séparer de son bébé.

Il faut dire qu'en même temps, les cheminots de Fives ont fait un travail extraordinaire. Ces 24 cheminots, avec le chef de gare ont pris tous les risques pour sauver des personnes car, s'ils étaient pris, ils auraient pu être fusillés ou déportés. Apparemment les choses se sont bien passées car ils étaient tellement bien organisés. Ils ont réussi à sauver cinquante enfants ce jour-là. Et je pense surtout à ces mamans, et à ma maman, qui, dans une telle situation alors que le seul espoir qui leur reste est leur enfant, sont amenées à accepter de se séparer de leur enfant. Elles savaient que si les enfants montaient dans le train en formation, ils ne reviendraient pas.

Ma maman a fini par accepter de donner le bébé. L'infirmière disait de donner le bébé car dans un camp il n'y aurait rien à manger pour lui, rien pour l'habiller, elle allait en souffrir et le bébé encore plus. L'infirmière, France Neubert, est retournée à la clinique pour obtenir la permission de ramener le bébé, permission qu'immédiatement elle a 
obtenue. Elle est revenue avec une bicyclette et un sac à dos. Comme elle avait un brassard de la Croix Rouge, elle a pu entrer facilement et elle est retournée près de ma mère. À ce moment, ma mère a encore hésité mais, devant l'insistance de l'infirmière, elle a cédé.

Le bébé est mis dans le sac à dos et dès qu'il y est, il se met à hurler. Un bébé que l'on met dans un sac à dos, ce n'est pas courant. Et là un autre miracle survient. Une locomotive haut-le-pied, à vapeur, passe devant la gare en crachant de la vapeur et en sifflant. Tout le monde se tourne pour regarder cette locomotive et l'infirmière en profite pour passer derrière tout le monde et quitter la gare. Mon petit frère Michel est amené à la clinique Ambroise Paré où on le sort de son sac.

Mon petit frère est resté cinq ans dans cette clinique Ambroise Paré. Il a été très bien soigné par les infirmières. Il était fragile et il paraît qu'il a refusé de rire et même de sourire pendant six mois. Il a été choyé et aimé, il s'en est sorti.

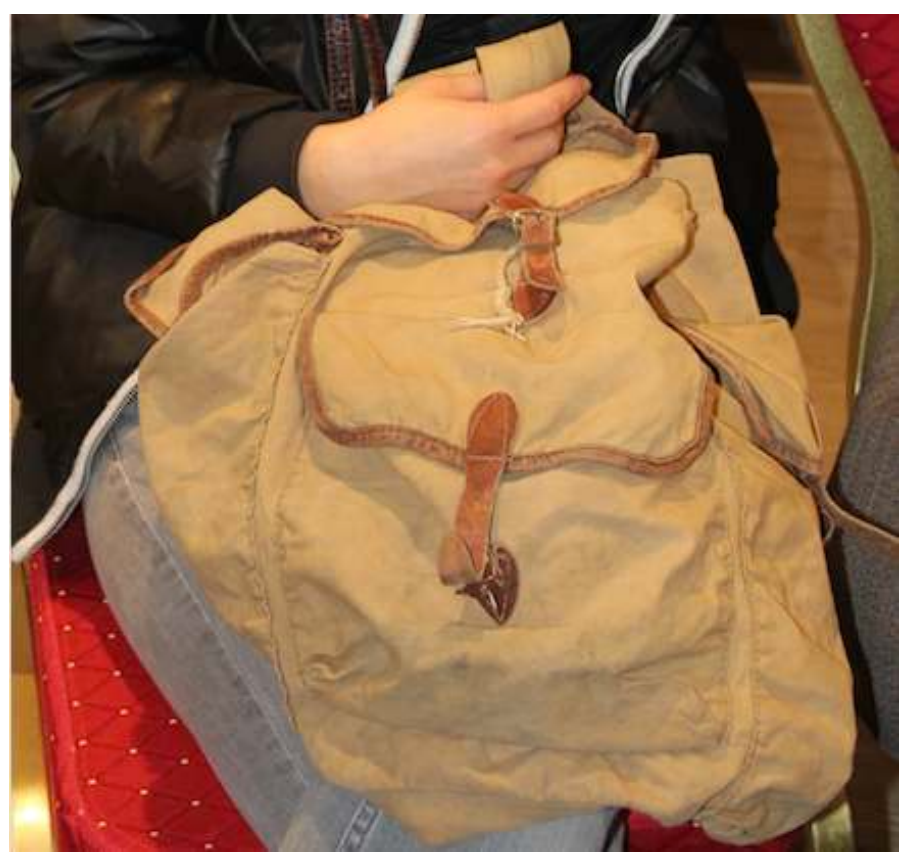

Sac à dos dans lequel Michel Baran, âgé de trois mois, fut sorti de la gare de Fives, le 11 septembre 1942, par France Neubert, infirmière à la clinique Ambroise Paré.

Photo de Monique Heddebaut, prise lors de la cérémonie du 10 septembre 2017 pour l'apposition d'une plaque en l'honneur des trois infirmières, $\mathrm{M}^{\text {elles }}$ Matter, Durrleman et Neubert, à l'EHPAD qui a été institué dans les locaux de la clinique. Le sac est présenté par la fille de Michel Baran. 
Et Georgette m'a emmené à Loon-Plage, un petit village près de Dunkerque puis jusqu'à un petit hameau, Pont-à-Roseaux, un tout petit hameau à trois $\mathrm{km}$ du village. C'était un endroit vraiment isolé : on franchit le watergang [fossé de drainage des champs de la Flandre maritime] et on pénétra dans une petite maison, chez la maman de Georgette. C'était une petite maison d'ouvrier agricole, avec un étage et un poêle typiquement flamand et sa cafetière toujours dessus.

Immédiatement, Georgette a expliqué à sa mère, Madeleine Franchois, une belle Flamande, une forte femme, pourquoi elle m'a amené et sa maman a accepté tout de suite de me garder. Il y avait aussi un petit garçon, un petit rouquin, Lionel, le petit frère de Georgette. Et Madeleine dit tout de suite à son fils : « Tu vas montrer les bêtes ». Lionel me fit entrer dans une étable. Ça puait! Je n'osais même pas entrer ! Et là de nouveau un miracle ! Dans l'étable, il y avait une cage à lapins et Lionel en sort une lapine blanche, la prend dans ses bras et me demande de la caresser. Mais je n'avais jamais caressé un lapin, j'avais peur. Alors il me prend la main et m'oblige à caresser ce lapin. Et ça a été une douceur inimaginable que j'ignorais. Ce fut une respiration de soulagement après toutes les affres que je venais de vivre.

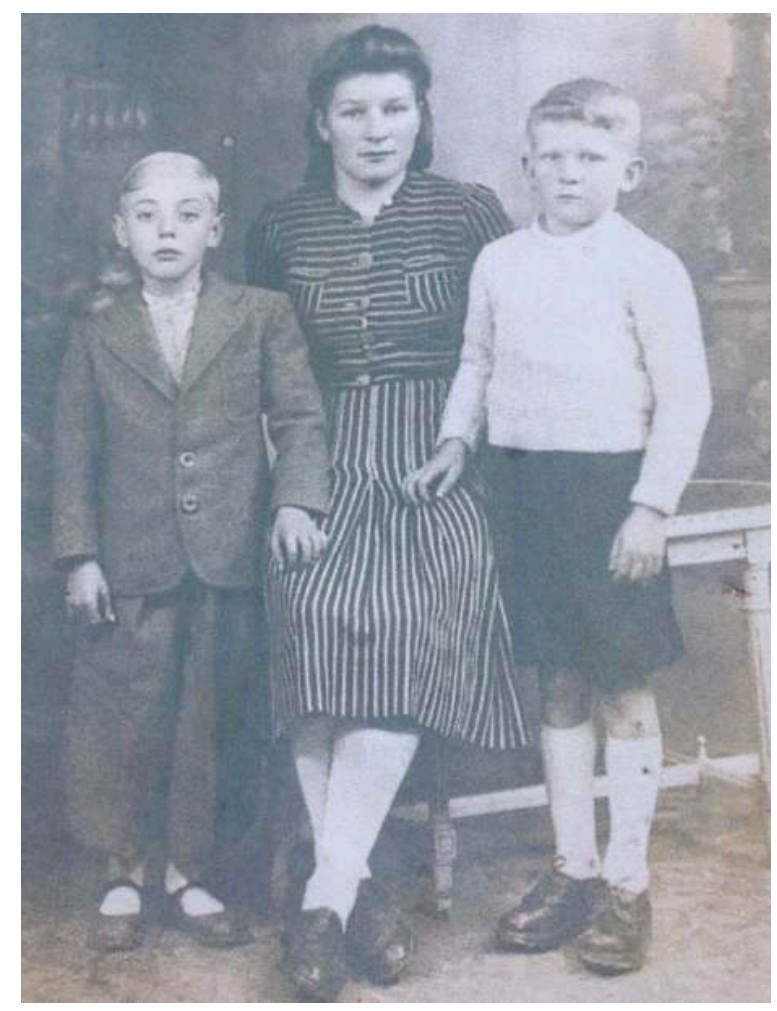

Georgette entourée de Lionel (à droite) et de Maurice (à gauche)

(archives familiales de Maurice Baran-Marszak) 
Près de la maison, il y avait deux grandes prairies et on jouait énormément quand on n'était pas dans la période des travaux agricoles. On jouait à la guerre ! Il n'y avait pas d'école, je suis allé très peu à l'école. On s'adonnait à tous les jeux. Au cerf-volant : il y avait tellement de vent. On fabriquait des fusils et des lance-pierres. On jouait des journées entières! Jouer, c'était aussi sérieux que de travailler. Il y avait des champs à perte de vue, on courait et on avait une grande liberté. C'était une liberté que je n'avais pas connue les années auparavant.

On moissonnait le blé et on le battait avec une batteuse qui allait de ferme en ferme. On récupérait la paille et les paillettes avec lesquelles on faisait les matelas. Chaque année, à la moisson, on vidait les paillasses, on lavait la toile et on les remplissait de paillettes. On n'avait pas de matelas, on était élevé à la dure. On était heureux !

Il y avait aussi une station d'écoute allemande et on allait voir comment les Allemands se camouflaient. Des avions alliés nous survolaient parfois, ils allaient bombarder l'Allemagne. Un avion a atterri devant la maison car il était en panne d'essence. Le pilote a été fait prisonnier. Il y avait encore le blockhaus avec l'artillerie allemande tournée vers la mer. Mais on ignorait les Allemands, comme s'ils n'existaient pas. Pourtant, ils ont mobilisé les hommes pour abattre des arbres et confectionner les poteaux Rommel sur les plages, des poteaux avec des fils de fer barbelés, en prévision d'un débarquement.

À la Libération, les troupes alliées sont arrivées et il y a eu un énorme drame pour la famille Franchois. Les Allemands, en quittant la région et en se retirant de la poche de Dunkerque, avaient miné les champs tout autour de la maison. Le cheval, guidé par M. Franchois, a marché sur une mine antichar et tous les deux ont été déchiquetés. C'était un drame car M. Franchois était le père qu'on admirait beaucoup dans ces familles agricoles, il avait un rôle important, on le respectait. C'était mon premier contact avec la mort. Et j'ai eu un gros chagrin car Lionel a pu se précipiter vers sa maman et se mettre à pleurer. Mais moi je ne pouvais pas, je n'avais pas le droit, elle n'était pas ma maman. Et j'ai renfermé mon chagrin car moi je croyais que j'étais le fils de la famille. Je n'étais pas le fils de la famille!

\section{Danielle Delmaire}

Cher Maurice, on va arrêter ici le récit à Loon-Plage et donner la parole à Jeannette. Sa famille est obligée de quitter Dunkerque et se rend 
à Cambrai chez un frère de la maman. Que se passe-t-il à Cambrai pour la famille Hubschman?

\section{Jeannette Rapoport}

On arrive : plus d'oncle ! Plus de famille ! Plus rien! Plus personne qui puisse nous aider.

Nous allons à l'école. Nous ne portons pas l'étoile juive, pendant toute la guerre. Mon père pensait qu'étant Français, il n'y avait aucun problème en ce qui nous concernait et il n'était pas question que nous portions l'étoile juive.

Comment avons-nous vécu ? C'est difficile à dire. Je me souviens que mon frère aîné [Bernard, né en novembre 1934] allait avec mon père récolter des épis de blé, ils glanaient. Papa ne pouvait certainement pas travailler puisqu'il avait reçu du commissariat de police de Cambrai l'obligation de ne pas être à la charge de la société. On n'avait rien. C'était tout à fait évident que l'on voulait nous faire mourir de faim puisque n'ayant plus la possibilité d'avoir une situation, on ne pouvait pas avoir un emploi en contact avec le public. Finalement, il fallait essayer de se débrouiller, en glanant, en travaillant. Où ? Comment ? J'avoue que je ne sais pas ce qu'a fait mon père. Je n'ai pas posé de questions à maman. Ce qui est sûr, c'est que nous, en tant qu'enfants, on ne se rendait compte de rien. On ne savait pas non plus ce que c'était être juif.

Donc on avait une vie, non pas insouciante car on était pauvre, on vivait dans une petite maison, à Cambrai, mais on était heureux, on avait nos parents, on allait à l'école. Je dois souligner le rôle extraordinaire que les enseignants ont joué pour nous, avant que papa soit déporté et aussi après et même davantage après. Ils nous ont toujours soutenus. Sachant qu'on était juifs, personne n'a jamais manifesté quoi que ce soit contre nous. Au contraire même, je pense qu'ils avaient une certaine affection pour nous. Ils voulaient nous aider, sans ostentation mais de façon pertinente : c'est ce que disent souvent les Justes et même les autres qui semblaient indifférents. Ils agissaient pour que les enfants et leurs parents soient heureux.

Comment cela se passait donc pour des enfants qui vont à l'école, qui ont leurs parents et pour qui, finalement manger du caviar ou manger une tartine, quand on a la chance de pouvoir manger une tartine, c'est bien, c'est très bien, ça suffit. L'essentiel est de se sentir sécurisés par la présence des parents autour de soi, d'aller à l'école et d'être aimé du 
corps enseignant, d'avoir des petits copains et des petites copines. Voilà, quand j'en parle maintenant, j'ai l'impression que c'était une vie sans histoire. Jusqu'à un certain moment.

C'est en juillet 1944. Je suis née en 1937, j'avais sept ans. Et je me rends compte qu'il y avait des tas de choses que je n'imaginais pas mais que j'avais comprises. Je me souviens brutalement. Je me promène avec papa dans les rues de Cambrai quand un SS lui met la main sur l'épaule. Alors papa me dit en yiddish que je comprends : "Sauve-toi, sauve-toi, va-t-en ». Et j'ai compris immédiatement ce qui se passait. Comment aije retrouvé la maison ? Je n'en sais rien. Pourquoi le SS ne m'a-t-il pas obligée à suivre papa? Je n'en sais rien. Et quand je suis arrivée à la maison, pourquoi ai-je dit à maman : «Tu sais maman, papa est en Allemagne »? Alors que je ne savais pas ce que c'était qu'être juif. En tout cas j'ai dit cela à maman, je m'en souviens encore, j'ai dit cette phrase-là.

Papa était au commissariat de Cambrai après que le SS l'ait pris. L'adjoint du commissaire de police, Monsieur Lecoultre qui connaissait papa, car papa s'exprimait très bien en français et il était très sociable, lui a dit : "Max, je vais t'ouvrir la fenêtre et sauve-toi, tu peux te sauver cette nuit». Et papa lui a répondu : "Cela ne servira à rien car ils viendront prendre ma femme et mes enfants ». Ça se passe au moment de son arrestation.

Le lendemain, maman nous emmène, mes deux frères et moi à la Kommandantur de Cambrai. Ça je m'en souviens aussi comme lorsque papa a été arrêté. Et elle dit au chef de la Kommandantur : «Emmenezmoi, je n'ai pas de famille, je n'ai aucun moyen de subsistance, j'ai mes trois enfants, vous avez pris mon mari, emmenez-moi ». Et je me souviens très bien du geste du chef de la Kommandantur qui, en nous regardant mes deux frères et moi serrés contre maman, a crié : « Raus », dehors ! Encore un mystère, pourquoi ? C'est vrai que cela se passait en juillet 1944 et le débarquement en Normandie avait déjà eu lieu, c'était donc déjà dans un contexte bien particulier. Est-ce que pour lui, les carottes étant cuites, cela ne valait plus la peine d'en faire plus? Je n'en sais rien. Est-ce qu'il a été ému ? Je n'en sais rien. En tout cas, il nous a obligés à sortir et, par la suite, maman s'est reprochée toute sa vie d'avoir eu ce geste de folie; elle disait: "Je nous amenais au feu, tous les quatre ».

Voilà, après, on se retrouve seuls, sans personne autour de nous, un peu comme des fétus de paille sur l'océan. 
J'ai oublié aussi de parler de ce qui s'est passé pendant les bombardements de Cambrai. Au printemps 1944, il y a eu des bombardements des alliés très importants à Cambrai, près de la mairie. Je me souviens en particulier d'un bombardement, durant lequel nous étions dans des abris situés sous la mairie, qui a provoqué un incendie épouvantable, tout près de l'endroit où nous étions. Et là je fus séparée de toute la famille. Les gens couraient partout et je me souviens que je me suis retrouvée seule en train de courir au milieu des flammes. J'ai retrouvé mes parents, combien de temps après? Je ne sais pas. Et pendant cette période de bombardements, mon frère aîné, qui était un petit galopin à l'époque même si après il s'est bien assagi, était en train de jouer au foot avec des copains, au jardin public. Sous un bombardement énorme, Bernard se souvient qu'il courait dans le jardin public de Cambrai au milieu des bombes qui tombaient de part et d'autre du jardin et des immeubles qui s'écroulaient. C'est ce qui fait que, même après la Libération lorsqu'il n'était plus nécessaire de dormir dans les abris, Bernard a continué à dormir dans les caves des maisons que nous pouvions occuper. Il a mis un temps énorme à remonter à la surface et à oser venir dormir comme tout le monde, alors que c'était la paix.

\section{Danielle Delmaire}

Il est temps maintenant de donner la parole à la salle, même si l'on vous écouterait encore longtemps tous les trois mais, auparavant, je souhaite résumer rapidement ce qu'il advint de chacun des témoins après la guerre.

Zelda rentre donc à Paris. Son père ne revient pas de déportation. Elle entreprend des études de lettres à la Sorbonne et elle devient professeur de lettres. Pas longtemps. Elle rencontre son mari avec lequel elle mène une vie heureuse, jusqu'à présent. Surtout, elle devient peintre, artiste, et s'adonne à la danse. À 94 ans, elle danse toujours, pleine de vie et elle est encore là pour évoquer devant nous son passé : son adolescence, sa jeunesse. Elle a un atelier de peinture au nom de Zelba (et non Zelda), 14 rue Mansart à Paris.

Pour Maurice, lorsque la guerre se termine, aucun de ses deux parents ne revient de la déportation. Il est un petit orphelin. Les infirmières protestantes qui ont recueilli son petit frère sont convaincues qu'il faut réunir la fratrie. Elles retrouvent Maurice et vont le chercher chez $\mathrm{M}^{\mathrm{me}}$ Franchois. Il est obligé de se séparer de la famille de Georgette. Mais les infirmières ont trouvé, pour les deux garçons, un couple dont le 
mari est juif et qui accepte de les adopter. Il s'agit de $\mathrm{M}$. et $\mathrm{M}^{\mathrm{me}}$ Marszak, d'où le double nom de Maurice: Baran-Marszak. Une troisième vie débute. C'est le titre de son livre : Le p'tit garçon aux trois vies, première vie avec ses parents biologiques à Dunkerque et Lille, deuxième vie dans la famille de Georgette à Loon-Plage, troisième vie avec son petit frère Michel et $\mathrm{M}$. et $\mathrm{M}^{\mathrm{me}}$ Marszak. Ces derniers lui permettent de faire des études de pharmacie et il devient ingénieur chimiste. Il épouse Zlata qui dessine, elle aussi, et elle a dessiné les trois vies du petit Maurice.

Maurice est toujours resté en relation avec Georgette et sa famille. Dès la fin des années 1980, Maurice entame des démarches auprès de Yad Vashem pour faire attribuer le titre de Justes parmi les Nations à Georgette, devenue épouse Vandenabaele, et ses parents, Madeleine et Marcel Franchois. Le titre a été décerné le 29 novembre 1990. Plus tard, le maire de Loon-Plage a accepté qu'un square de sa ville porte le nom des Franchois. Il a été inauguré, en présence de Maurice et son épouse Zlata, le 10 novembre 2018.

Jeannette ne revoit pas son papa qui ne revient pas de déportation. À la Libération, sa maman est complètement seule pour élever ses trois enfants en bas âge : l'aîné a 10 ans. Elle n'a aucune aide mais avec ténacité et en faisant les marchés, elle parvient à faire vivre sa famille. Malgré une grande précarité, Jeannette entreprend des études de dentiste et elle ouvre un cabinet. Ses deux frères font également des études supérieures. Quelques mois après la guerre, en 1945, Yekiv le frère de sa maman, rentrant de Bergen-Belsen, retrouve leur trace à Cambrai. Puis il s'est marié et s'est installé en Israël. Jeannette se marie à son tour et fonde une famille heureuse.

$* * * * * * * * * * * * * * * *$

\section{Publications antérieures}

Maurice a publié ses souvenirs :

- Baran-Marszak Maurice, Histoire d'un enfant caché du Nord. Familles entre amour et silence, (1942-1947), Paris, éd. Le Manuscrit, 2014, 180 p. Préface de Serge Klarsfeld.

- Baran-Marszak Maurice, Le p'tit garçon aux trois vies, chant de la terre, Paris, éd. Pétra, 2019. Illustrations de Zlata Baran-Marszak. Préface de Serge Klarsfeld. 
Jeannette a également écrit ses souvenirs qui, malheureusement, sont restés sous forme de tapuscrit, non publié.

Zelda a publié un livre de reproduction de ses peintures :

- Segouriano Zelda, Zelba 2020, CEWE (réalisation d'albums de photos).

$* * * * * * * * * * * * * * * * * *$

\section{Remarques à propos des témoignages}

Ces témoignages appellent, de la part de l'historien, plusieurs remarques.

Nous avons pu écouter et entendre les récits de trois vies qui se ressemblent partiellement : ils évoquent les persécutions raciales vécues par trois enfants, mais les décisions prises par les parents, face à des dangers redoutables, et/ou les aléas des mesures imposées par les administrations allemandes et/ou françaises font que, finalement, chaque récit est unique.

Dans leur enfance, les trois témoins partagent une vie heureuse à Dunkerque. Leurs parents, immigrés de Pologne ou de Turquie, avaient mis tous leurs espoirs dans le régime démocratique de la Troisième République française, où « Dieu est heureux » disait le papa de Jeannette qui n'avait pas hésité à combattre pour cette France, jusqu'en Indochine. Quant à sa maman, elle avait fui un avenir fait de servitude. Les parents étaient convaincus que leurs enfants nés en France, donc Français, étaient à l'abri de toute discrimination. Et c'était sans doute le cas à Dunkerque, dans les années 1930, puisque ces familles connaissaient le bonheur, les photos de la famille Baran sur la plage l'attestent, malgré la dureté de la condition de marchand forain. Il en est de même des photos de Jeannette.

Avec la déclaration de la guerre, des nuages commencent à assombrir l'horizon de ces immigrés. Toujours fidèle à sa nouvelle patrie, 
Meir Hubschman, le papa de Jeannette, revêt de nouveau l'uniforme du soldat et combat pour la défendre. La situation devient complètement chaotique avec le bombardement du port de Dunkerque dans le cadre de l'opération Dynamo qui doit permettre le rapatriement, vers l'Angleterre, des troupes alliées en pleine déroute. C'est une situation tout à fait dramatique que vit toute la population locale : les juifs et les non juifs. «C'était horrible, il y avait des bombardements tous les soirs» se souvient Zelda et «nous nous réfugions à la cave » rappelle Maurice. Tous deux connaissent la fuite de l'exode. Ces bombardements commencent à anéantir le bien-être familial d'avant-guerre : la famille de Maurice doit quitter son domicile pour se réfugier à Lille, tandis que, dans la débâcle, Zelda perd sa mère. Étonnamment, la famille de Jeannette reste à Dunkerque sans être inquiétée, momentanément. Ce n'est que dans les derniers jours de 1942 que la famille doit quitter le littoral sans disparaître puisqu'elle doit préciser où elle se réfugie. Pourtant, dès décembre 1940, les familles juives, immigrées et françaises, de Boulogne et des environs sont arrêtées et dirigées vers un camp de regroupement à Troyes. Le littoral devait être judenrein ! (voir l'article de Rudy Rigaut, supra).

Aucune des trois familles n'a tenté de rejoindre la zone libre, soit en 1940, soit à l'été 1942 lorsque la persécution devient plus menaçante, comme l'ont fait plusieurs autres familles juives de la région. Le papa de Maurice y a bien songé mais malheureusement le passeur s'est révélé être un complice des bourreaux. Éliezer Segouriano, le père de Zelda, et Meir Hubschman semblent ne pas avoir projeté un tel passage en zone sud - au demeurant très risqué pour une famille avec trois enfants en bas âge - tant ils ont encore confiance en la France.

À partir de l'été 1940, les parcours divergent donc mais ils restent dans un territoire restreint, celui du département du Nord qui désormais dépend du commandement militaire allemand de Bruxelles. Si bien que l'historien de la région peut répertorier trois parcours différents face à la persécution antijuive mise en place dans le département.

Les trois témoins sont victimes des rafles mais de trois rafles différentes : la famille de Maurice est touchée par la grande rafle du 11 septembre 1942 qui ravage les communautés encore existantes dans le Nord et le Pas-de-Calais ; Zelda et son père sont emportés par la rafle d'octobre 1943 qui broie les familles originaires de Turquie et de Hongrie, y compris les enfants nés en France donc Français, alors 
qu'elles pouvaient, éventuellement, se croire à l'abri; enfin le papa de Jeannette, lui qui a servi militairement son pays d'accueil, lui qui avait une confiance inébranlable envers la France républicaine, est victime d'une arrestation individuelle. Sauf Zelda, aucune des personnes arrêtées n'a survécu aux camps. Toutes ces arrestations se déroulent en dehors du calendrier des arrestations en France mais toutes les personnes arrêtées passent pas la Caserne Dossin de Malines (voir l'article de Laurence Schram, supra).

Dans le reste de la France, l'été 1942 s'est déjà révélé meurtrier pour de très nombreuses familles juives avec, les 16 et 17 juillet 1942, la rafle du Vel-d'Hiv en zone occupée et les rafles d'août 1942 en zone sud. Dans les tout premiers jours de septembre 1942, les familles juives du Nord et du Pas-de-Calais pouvaient encore espérer échapper aux rafles et aux arrestations. Mais déjà, informés de ce qui se passe dans le reste de la France et s'ils ont entendu les appels des évêques qui ont condamné les rafles de l'été $1942^{2}$, en zone libre, ou s'ils ont pris conscience des dangers par un engagement dans la Résistance, des Nordistes vont alors se mobiliser pour secourir les proscrits.

Aussi les trois familles ont-elles pu bénéficier de "réactivité sociale» comme la décrit Jacques Semelin ${ }^{3}$. À commencer par ces cheminots qui se mobilisent en gare de Fives pour soustraire plusieurs dizaines de personnes du train de la déportation et leur offrir des refuges. Des réseaux se sont alors constitués: protestant autour des pasteurs Pasche et Nick et des infirmières de la clinique Ambroise Paré ; catholique avec l'abbé Stahl qui cache, dans son patronage, des enfants juifs rescapés de la rafle; mixte dans le comité de sauvetage qui se met en place au lendemain de la rafle et qui réunit des hommes et des femmes issus d'horizons divers, y compris juif.

Outre ces réseaux, des individus, voisins ou inconnus, prêtent leur concours pour sauver des vies : c'est Georgette qui sort le petit Maurice de la gare; ce sont aussi ses parents qui, sans hésitation, ouvrent leur porte à l'enfant bouleversé ; c'est le garde en gare de Fives qui laisse

\footnotetext{
${ }^{2}$ L'appel le plus retentissant fut celui de Mgr Saliège de Toulouse, le 23 août 1942, lettre qui fut lue dans les paroisses du diocèse. Lire Sylvie Bernay, L'Église de France face à la persécution des juifs, 1940-1944, Paris, CNRS éditions, 2012.

${ }^{3}$ Jacques Semelin, La survie des juifs en France, 1940-1944, Paris, CNRS éditions, 2013 [2018]. L'auteur avance des hypothèses tout à fait pertinentes pour mieux comprendre les actes des sauveteurs et des personnes qui ont aidé à la survie des juifs. Je reprends volontiers sa grille d'analyse.
} 
passer Georgette avec « le gamin qui doit pisser »; c'est France Neubert qui passe les barrages de la gare avec le petit Michel dans son sac à dos ; ce sont les infirmières de la clinique Ambroise Paré qui recueillent le bébé ; c'est encore l'adjoint du commissaire de police à Cambrai qui offre la fuite au papa de Jeannette; enfin c'est l'Allemand qui met la maman et ses trois enfants hors de son bureau. Il est vrai que pour ce dernier exemple, comme le souligne Jeannette, la situation se détériore pour les Allemands et la police française ; l'heure des comptes arrive probablement, la prudence s'impose donc. À l'inverse, les pères de ces trois familles, et Zelda également, sont victimes d'Allemands et de leurs suppôts, sans secours possible.

Pour que cette « réactivité sociale » puisse fonctionner, il fallait, toujours selon Jacques Semelin ${ }^{4}$ la présence de «quatre personnages clés » : l'« ange gardien », l' « hôte » ou l'« hôtesse », le « faussaire » et le «passeur de frontières ». Les trois témoins ne mentionnent pas le recours à un «faussaire » fabriquant de faux papiers (cartes d'identité ou cartes d'alimentation). Au contraire, le papa de Zelda, soucieux de se conformer à la législation en vigueur, établit de vraies cartes d'identité. Celle de Zelda date du 11 octobre 1941, elle est alors âgée de 16 ans, et la carte est renouvelée le 3 mai 1943, tamponnée du sinistre «JUIVE » en rouge, quelques mois avant l'arrestation. Quant au «passeur de frontières », seul le papa de Maurice y a eu recours, ni Meir Hubschman, ni Éliezer Segouriano n'ont songé à franchir les lignes de démarcation, selon les souvenirs de leurs enfants. Il est vrai que jusqu'à la fin de l'année 1942, lorsque les Allemands occupent aussi la zone libre, il faut franchir une double ligne de démarcation, c'est aussi la particularité de la région rattachée au commandement militaire de Bruxelles d'être cernée, au sud, par une ligne de contrôle. Le danger est donc double pour les voyageurs clandestins. Il se complique encore lorsque le passeur n'est pas fiable. Dans ce cas, la fuite équivaut à l'arrestation! C'est le sort qui s'abat sur le papa de Maurice qui espérait sauver sa famille.

En revanche, l'« ange gardien » et l' « hôte » ou l' " hôtesse » sont bien présents dans l'entourage des trois témoins. Comme «ange gardien » surgit tout de suite le personnage de Georgette qui multiplie les gestes salvateurs, insignifiants semble-t-il parfois, pour adoucir le quotidien de son protégé. Elle l'emmène au cinéma, au square, sur les

${ }^{4}$ Ibid. 
manèges, faisant fi de l'interdiction et dissimulant l'étoile. Elle parcourt la campagne à bicyclette pour ravitailler la famille. Elle est présente lors de l'arrestation et c'est elle qui prend des initiatives à la place de la maman affolée. Elle répond encore à l'appel au secours de son employeuse pour accourir à la gare et exfiltrer l'enfant. Dans le témoignage de Maurice se profile encore un autre "ange gardien»: France Neubert, l'infirmière qui parvient à convaincre la maman de se séparer de son bébé. Elle fait d'ailleurs preuve d'obstination pour décider la maman bien réticente. Comme les cheminots de la gare de Fives, cette jeune fille pressent le pire pour ces raflés, massés dans le train.

L'adjoint au commissaire de police de Cambrai est aussi l'" ange gardien » qui se tient auprès du père de Jeannette. La tentative de sauvetage a échoué à cause du souci de préserver la famille. L'échec ne peut pas être condamné. En juillet 1944, la connaissance du véritable sort des personnes raflées reste encore floue et indéterminée. Meir Hubschman réagit dans l'instant immédiat et il pense prioritairement à sa femme et ses enfants. C'est sans doute cette même angoisse qui guide des parents dans leur refus de confier leurs enfants à des cheminots de la gare de Fives, des inconnus ${ }^{5}$.

L' « ange gardien » n'est peut-être pas toujours la personne qui a le geste salvateur. Les instituteurs qui ont réconforté Jeannette et ses frères peuvent, me semble-t-il, être qualifiés d'« anges gardiens ». Le réconfort, l'attention singulière qu'ils accordent à leurs élèves particuliers sont des gestes qui procurent aux enfants un sentiment de sécurité (c'est le mot employé par Jeannette) : il aide à surmonter la persécution.

Face au danger et à l'impossibilité de subvenir à leurs besoins, les familles des trois témoins ont recours à l'« hôte » ou l'« hôtesse » qui ouvrira sa porte. C'est bien sûr le couple Franchois qui pose peu de questions à leur fille Georgette lorsque celle-ci leur confie Maurice. Le geste est spontané, irréfléchi. Certes, les Franchois vivent à la campagne et la nourriture ne semble pas manquer : ils ont un potager et des lapins, certes aussi le hameau de Pont-à-Roseaux est isolé mais le danger est quotidien lorsque l'on sait que les Allemands sont installés près de la ferme. L' « hôtesse » est la dame qui loge Zelda et son papa, rescapés des

\footnotetext{
${ }^{5}$ Dans son témoignage, Jacqueline Mandelbaum-Bleibtreu relate les hésitations, voire le refus, de parents pour confier leurs enfants aux cheminots; Daniel Mandelbaum et Jacqueline Mandelbaum-Bleibtreu, "Le 11 septembre 1942. Les cheminots et les déportés juifs en gare de Fives-Lille », Tsafon, revue d'études juives du Nord, $\mathrm{n}^{\circ} 76$, automne 2018-hiver 2019, p. 169-176.
} 
bombardements qui détruisent Dunkerque en juin 1940. À l'été de cette année-là, le danger bien que présent n'est pas encore pesant mais, après la grande rafle du 11 septembre 1942, la dame du 26 de la rue de Fleurus à Lille, qui les héberge jusqu'à leur arrestation, est bien l' " hôtesse » qui prend des risques pour les aider. Sans ces « personnages-clés», les trois témoins ne seraient plus parmi nous pour évoquer la persécution dont ils furent victimes. Tous les trois l'ont rappelé.

Outre ces «personnages-clés» qui ont agi par « réactivité sociale », tous les trois témoins évoquent la "chance» qui à plusieurs reprises les a tirés d'un très mauvais pas. Jacques Semelin remarque, à juste titre, que l'histoire de la persécution des juifs est jalonnée de ces coups de chance ou au contraire de malchance : se trouver par hasard là où il fallait ou bien là où il ne fallait pas! La malchance vient bouleverser les familles comme l'arrestation inopinée de Meir Hubschman ou celle de Zelda et son papa. Mais malgré cette fatalité, les trois témoins utilisent ce terme alors que, finalement, leur sort relève plutôt de la malchance : celle de subir une législation inique. Mais il est vrai que pour survivre il fallait rencontrer la «chance ». Revoyons ces multiples occasions où la « chance » a sauvé les témoins.

Pour Maurice, la présence de Georgette et son esprit d'initiative est incontestablement une chance ainsi que la chaleur de l'accueil de la famille Franchois. L'enfant ne sort pas indemne du drame qu'il vient de vivre mais pouvoir trouver un foyer heureux, qui lui procure un réconfort constructeur, est ressenti comme une chance. Il évoque d'ailleurs ce passé d'enfant chti à la campagne avec beaucoup d'émotion, voire de tendresse. Le sauvetage a pu aussi réussir grâce à d'autres coups de chance : le garde qui autorise Georgette à sortir pour «faire pisser le gamin », la locomotive haut-le-pied qui se met à siffler et à cracher de la vapeur au moment précis où France Neubert doit quitter la gare avec le bébé qui crie dans son sac à dos.

Pour Zelda, la très grande chance vient de la nationalité turque de ses parents, elle-même identifiée turque alors qu'elle est née en France et qu'elle possède une carte d'identité française, délivrée par la préfecture du Nord! Cette chance lui permet d'être encore en vie 76 ans après l'arrestation. Elle est dirigée vers le camp de concentration de Ravensbrück au lieu du camp de concentration et d'extermination d'Auschwitz. Dans le camp même, elle reconnaît avoir encore bénéficié de la chance, d'abord lorsqu'elle est repérée par une garde qui l'envoie 
travailler dans une usine Siemens où le régime est un peu moins pénible, puis lorsqu'elle est remarquée pour servir de monnaie d'échange et libérer des prisonniers allemands incarcérés à Istanbul. Elle en conçoit actuellement une certaine révolte : survivre sur des coups de chance lui paraît inadmissible, inconcevable. "C'est tout de même une grande chance. Et ce qui me révolte c'est que si j'avais été arrêtée en tant que Française, je ne serais pas en train de parler en ce moment, je serais morte à Auschwitz » s'exclame-t-elle.

Pour Jeannette, la rencontre avec la chance a lieu dès 1940 lorsque sa famille n'est pas obligée de fuir Dunkerque et lorsque le cocon familial peut se reconstituer à Cambrai, malgré la douleur de constater la disparition d'un petit cousin et de ses parents. Mais la grande chance qu'elle mesure a posteriori réside dans deux événements: sa non arrestation lorsque son papa lui ordonne de fuir et surtout le refus de l'employé de la Kommandantur qui met dehors une mère de famille perdue et ses trois enfants en bas âge.

Il est arrivé, parfois et rarement sans doute, que des familles juives ou des individus juifs n'aient pas été arrêtés car oubliés ${ }^{6}$ !

Et c'est probablement ces coups de chance qui interpellent encore, jusqu'à ce jour, les témoins. Ils se posent toujours des questions auxquelles ils ne peuvent apporter de réponse. Ce sont les trous dans les mailles du filet administratif qu'évoque Jeannette, trous salvateurs eux aussi et que Jacques Semelin n'évoque pas dans ses analyses pourtant pertinentes.

C'est le cas de la famille de Jeannette qui doit la vie à ces failles. Bien qu'elle soit localisée à Dunkerque, elle reçoit tardivement l'ordre de quitter le littoral. À l'été 1942, la famille Hubschman semble oubliée de l'administration et elle échappe donc à la grande rafle du 11 septembre 1942 qui décime toutes les communautés du Nord et du Pas-de-Calais. Mais il est vrai, que dès la fin de l'année 1940, le littoral est considéré comme judenrein et donc probablement l'administration allemande pense ne pas avoir à agir à Dunkerque et en d'autres villes de la côte (voir l'article de Rudy Rigaut, supra). Pourquoi questionne fréquemment Jeannette. La réponse ne vient pas. Maurice et Zelda s'interrogent également sur des moments incroyables.

\footnotetext{
${ }^{6} \mathrm{~J}$ 'ai pu recueillir le témoignage d'une dame qui a vécu à Lille durant toute la guerre, sans vraiment se cacher mais surmontant quotidiennement la peur d'être arrêtée et qui, finalement, ne l'a pas été. Ce témoin souhaite conserver l'anonymat.
} 
Outre les questions sans réponse, pour Zelda restituer le passé concentrationnaire de Ravensbrück semble presqu'impossible. Les mots viennent difficilement et le récit s'interrompt par un : «Comment vous dire ? ».

Pour le Nord, il faut encore relever les "facteurs religieux et culturels ", tels que les définit Jacques Semelin. Le contexte religieux est prégnant dans le sauvetage à la gare de Fives-Lille qui se trouve dans un quartier où vit une communauté protestante très unie autour de son pasteur, Henri Nick, et entourée d'une population ouvrière rarement indifférente à la vie politique et syndicale. C'est d'ailleurs dans ce quartier que les cheminots trouvent les premiers secours pour cacher puis disperser leurs protégés (voir l'article de Monique Heddebaut, supra). En outre l'action du pasteur Nick est relayée par celle du pasteur Pasche et des infirmières protestantes de la clinique Ambroise Paré.

Le facteur culturel prend aussi de l'importance. En effet, la population nordiste reste imprégnée des souvenirs de l'occupation de la guerre précédente. Il en résulte un esprit volontiers indépendant et hostile à l'égard du « Boche ». L'esprit frondeur habite complètement Georgette qui se soucie bien peu des interdits, au risque d'une arrestation, lorsqu'elle emmène Maurice partout où il lui est interdit de séjourner. De même faut-il mettre en avant une culture volontiers républicaine, ancrée à gauche, qui caractérise les habitants du Cambrésis ? Ce qui expliquerait - partiellement sans doute - la sympathie que les enseignants manifestent à l'égard des enfants Hubschman. "Aux côtés des parents d'accueil, l'institutrice ou l'instituteur ont été d'autres figures de parents de substitution pour ces enfants $[\ldots] »^{7}$.

Enfin retenons de ces témoignages d'enfants l'importance de la présence des parents. Dans la détresse de l'arrestation, Maurice s'accroche à la jupe de sa maman et il ne la quitte que pour suivre Georgette, sa «grande sœur». L'angoisse et la peur disparaissent dès lors qu'il retrouve des parents : $\mathrm{M}$. et $\mathrm{M}^{\mathrm{me}}$ Franchois. Et pourtant, malgré

\footnotetext{
${ }^{7}$ Patrick Cabanel, Histoire des Justes en France, Paris, Armand Colin, 2012, p. 303. L'auteur consacre les p. 298-305 à la «La République des Justes: instituteurs et institutrices ». Dans cette étude, il insiste sur la présence rassurante des enseignants de l'école laïque ; imprégnés des valeurs républicaines, ils ont sauvé des enfants et souvent ils leur ont apporté un soutien moral. L'historien déplore, à juste titre, l'effacement de ce corps de métier dans l'historiographie des Justes, alors que les religieux sont souvent mis en avant.
} 
la chaleur de ce foyer, Maurice s'aperçoit, à la mort de Marcel Franchois, qu'il n'est pas complètement le fils de Madeleine Franchois comme il l'avait espéré. Alors la perte, momentanée semble-t-il, du lien familial plonge le petit Maurice dans une nouvelle tristesse. Car c'est bien la présence des parents qui rassure et stabilise l'enfant. Jeannette le dit admirablement lorsqu'elle oublie la misère matérielle (une simple tartine à manger) tant la misère affective est pire. «[...] on était pauvre, on vivait dans une petite maison, à Cambrai, mais on était heureux, on avait nos parents, on allait à l'école» déclare-t-elle. Il faut alors mesurer le désarroi des enfants qui ont assisté à l'arrestation des parents pour ne plus les revoir.

En conclusion, nous sommes invités à nous imprégner de ces témoignages d'enfants victimes de la persécution raciale des nazis. Les valeurs républicaines ont été bafouées mais, dans le combat pour les maintenir et les respecter, des gens simples venus de tous bords, politisés et syndiqués ou sans engagement, croyants ou athées, se sont manifestés souvent spontanément et sans hésitation. C'est d'eux aussi que les témoins ont parlé dans leurs souvenirs. Pour l'historien, le témoignage n'est pas une seule évocation du passé. Le témoignage permet d'analyser des situations familiales et/ou sociales exceptionnelles et des stratégies de survie pour échapper à la mort programmée.

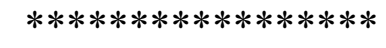

\section{Convois des déportés cités dans les témoignages}

\section{Les parents de Maurice}

BARAN Abram, Jankiel, né le 19 avril 1901, convoi I parti de Malines le 4 août 1942, arrivé à Auschwitz le 5 août 1942, nº 363.

BARAN Fanny, née YERKOWSKI le 30 octobre 1913, convoi X parti de Malines le 15 septembre 1942, arrivé à Auschwitz le 17 septembre $1942, n^{\circ} 791$.

\section{Zelda et son père}

SEGOURIANO Éliezer, né le 10 novembre 1892, convoi Z parti de Malines le 13 décembre 1943, $\mathrm{n}^{\circ} 108$.

SEGOURIANO Zelda, Simone, née le 9 janvier 1925, convoi Z parti de Malines le 13 décembre 1943, n 109. 


\section{Le papa de Jeannette}

HUBSCHMAN Meir, né le 7 novembre 1901, convoi XXVI parti de Malines le 31 juillet 1944, arrivé à Auschwitz le 2 août 1944, nº 469. C'est l'avant-dernier convoi qui part de Malines.

\section{L'oncle de Jeannette et sa famille}

MACNER Joseph, né le 15 octobre 1897, convoi VII parti de Malines le $1^{\text {er }}$ septembre 1942, arrivé à Auschwitz le 3 septembre 1942, n 37 (rentré). Il n'a donc pas été raflé le 11 septembre 1942 mais avant (voir l'article de Laurence Schram, supra).

MACNER Chaja, née GLASS le 12 août 1908, convoi X parti de Malines le 15 septembre 1942, arrivé à Auschwitz le 17 septembre $1942, n^{\circ} 331$.

MACNER Marcel, né le 13 août 1937, convoi X parti de Malines le 15 septembre 1942, arrivé à Auschwitz le 17 septembre 1942, nº 332.

$* * * * * * * * * * * * * * * *$

\section{Description des convois}

Selon Maxime Steinberg et Serge Klarsfeld, Mémorial de la Déportation des Juifs de Belgique, Bruxelles, édité par l'Union des Déportés juifs en Belgique et Filles et Fils de la Déportation, 1982, introduction.

Compléments d'information à partir du site numérique de la Caserne Dossin : kazernedossin.eu

\section{Convoi I}

Il est constitué de 999 personnes dont 140 enfants de moins de 16 ans, la plupart furent convoquées pour une «mise au travail » sur ordre de la police de sécurité dirigée par le SS Ernst Ehlers. L'Association des Juifs de Belgique (AJB), créée sur ordre du commandement militaire de Bruxelles, a distribué les convocations de « mises au travail ».

La liste est terminée le 31 juillet, complétée par les noms de 163 déportés sans convocation mais raflés en gare d'Anvers. 744 matricules sont délivrés tandis que 254 personnes disparaissent sans laisser de traces. À la Libération, huit survivants sont dénombrés, le père de Maurice n'est pas parmi eux. 


\section{Convoi VII}

1000 personnes dont 344 enfants en font partie, elles ont été raflées à Anvers dans la nuit du 28 au 29 août 1942, avec l'aide de la police belge réquisitionnée pour l'occasion. Avant d'arriver à Auschwitz, le convoi fait un arrêt à Kozel qui se trouve à $120 \mathrm{~km}$ et où est opérée une première sélection. De là, les déportés sont dispersés vers d'autres camps dépendant d'Auschwitz. Il n'y a que 15 survivants à la Libération dont fait partie Joseph Macner.

\section{Convoi X}

Il emporte 1047 personnes dont 229 enfants. La plupart ont été raflés par des SS flamands et la Feldgendarmerie, d'autres ont été raflés dans le Nord et le Pas-de-Calais. À l'arrivée à Auschwitz, 331 matricules sont délivrés, 25 personnes survivent à la Libération. Fanny Baran, Chana Macner et le petit Marcel ne sont pas parmi elles.

\section{Convoi XXVI}

La liste aligne 563 noms dont ceux de 47 d'enfants. Elle concerne des juifs qui bénéficient d'une protection ce qui leur permet de rester dans la légalité. Mais cette protection ne les épargne pas de la déportation. 361 matricules sont délivrés, 187 déportés survivent mais ce n'est pas le cas de Meir Hubschman.

\section{Convoi Z du 13 décembre 1943}

Il emporte 132 ressortissants juifs hongrois ou turcs, "protégés » pour des raisons diplomatiques. Les hommes sont dirigés vers Buchenwald, les femmes et les enfants vers Ravensbrück. À la Libération, 74 déportés ont survécu mais la plupart ont été transférés à Bergen-Belsen. Zelda dirigée vers Istanbul fait partie de ces survivants ainsi que Lili Leignel, née Rosenberg, sa maman et ses deux petits frères. 


\section{Les Orphelins}

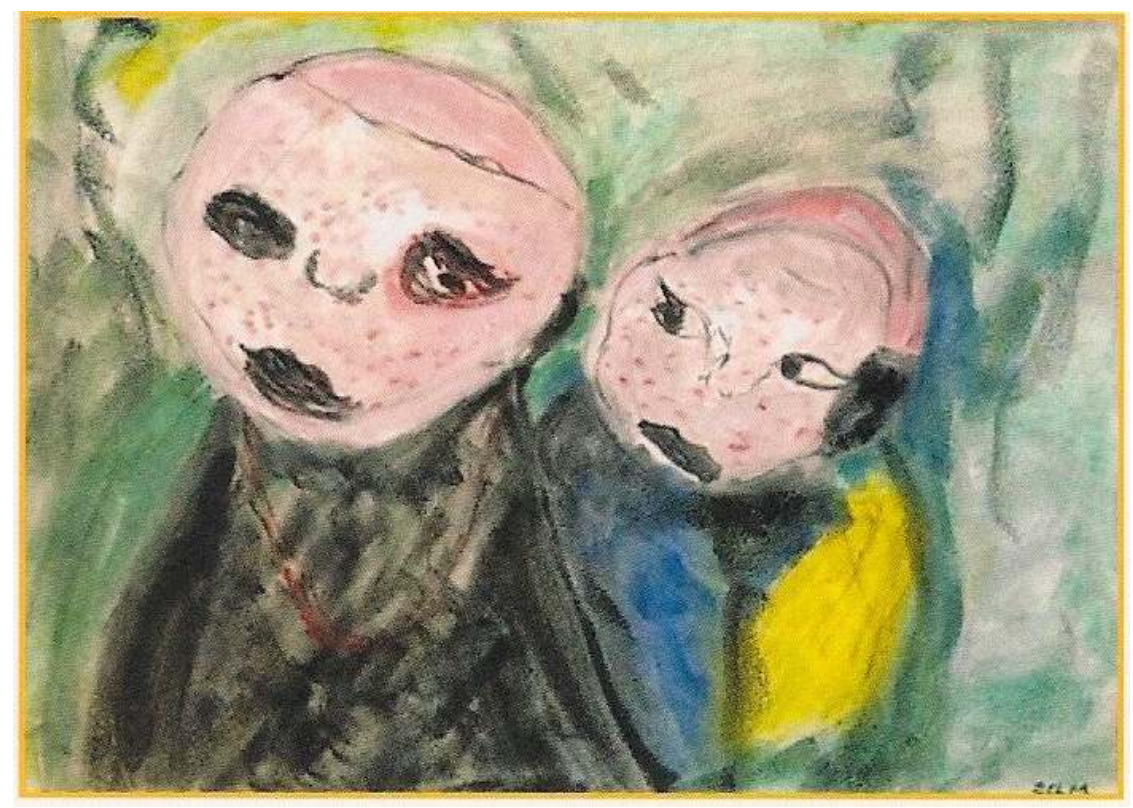

Acrylique sur toile $42 \times 52$

Zelba 2020

\section{CEWE}


Tsafon 79 : La persécution vécue par trois enfants juifs, dans la zone rattachée à Bruxelles

Euvre sans titre,

réalisée quelques jours avant la rencontre

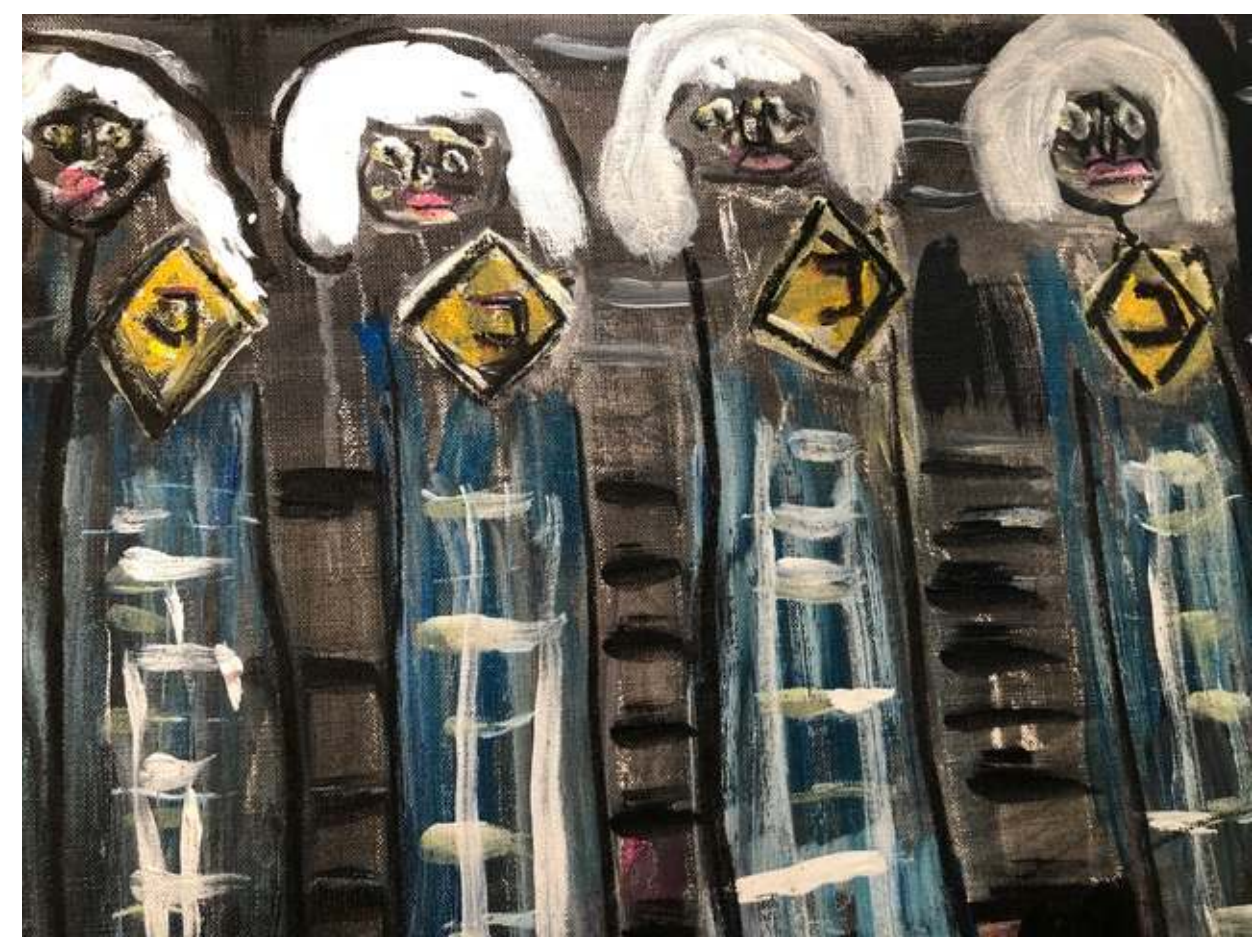

C'est la seule œuvre que Zelda Segouriano

a effectuée sur le thème de la déportation.

Jamais, avant son témoignage, elle n'avait peint sur ce thème.

« Elle n'a pas besoin de titre, elle parle d'elle-même » Zelda. 
La famille Franchois pendant la guerre

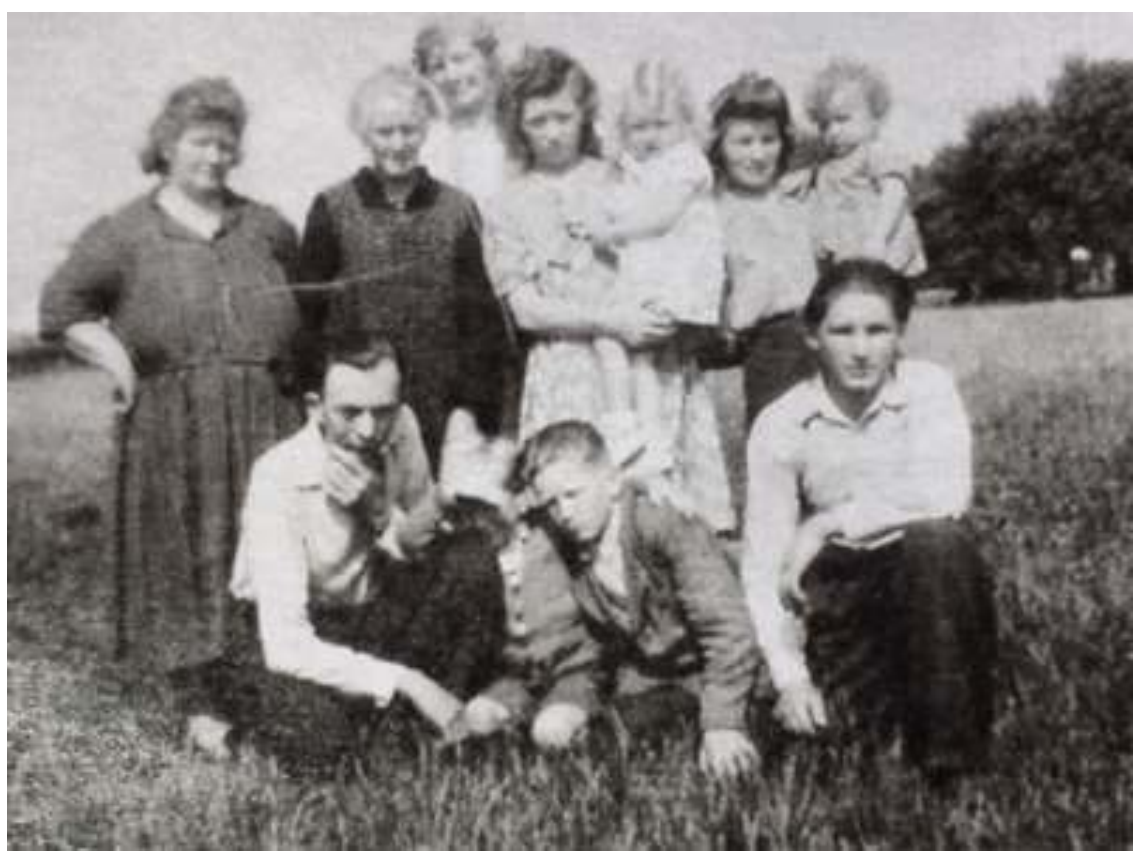

Georgette se tient debout à droite avec un enfant dans les bras Madeleine, sa maman, est à gauche, debout, mains sur les hanches

(archives familiales de Maurice Baran-Marszak)

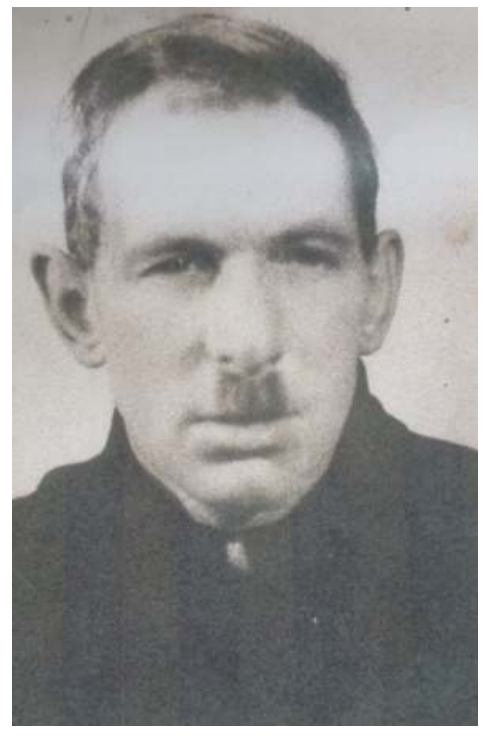

\author{
Marcel Franchois \\ papa de Georgette \\ (archives familiales \\ de Maurice Baran-Marszak)
}


Tsafon 79 : La persécution vécue par trois enfants juifs, dans la zone rattachée à Bruxelles

Georgette reçoit le diplôme de Juste parmi les Nations

(archives familiales de Maurice Baran-Marszak)

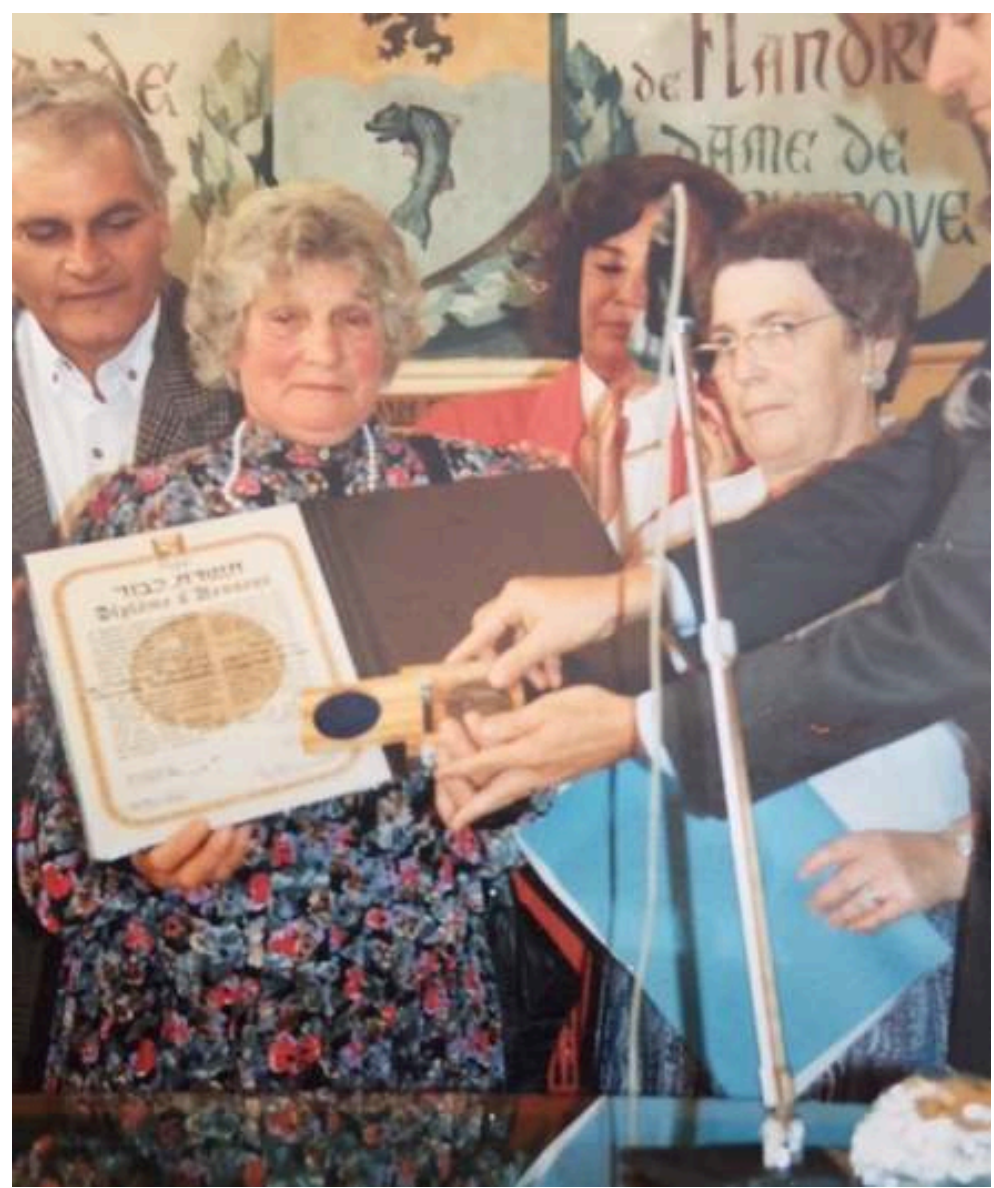

C'est le 29 novembre 1990 que Yad Vashem a décerné le titre de Justes parmi les Nations à Georgette

(devenue épouse Vandenabeele) et à ses deux parents, Madeleine et Marcel Franchois

Un square Franchois a été inauguré à Loon-Plage le 10 novembre 2018 


\section{L'amour parental sécurise l'enfant}

Texte de Meir Hubschman, au dos de la photo de Jeannette avec son vélo (archives familiales de Jeannette Rapoport)

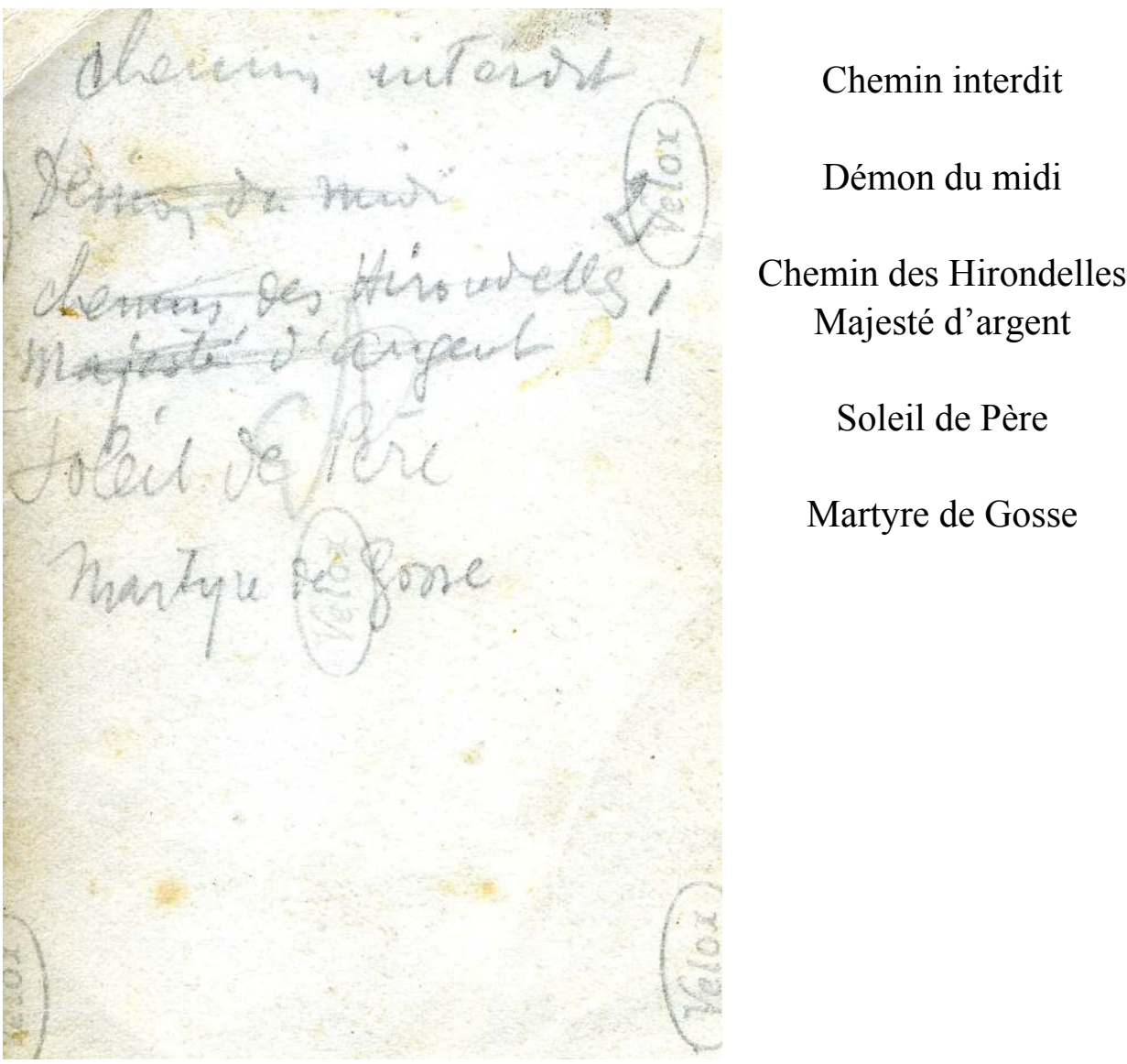

« On était pauvre, on vivait dans une petite maison, à Cambrai, mais on était heureux, on avait nos parents...» 